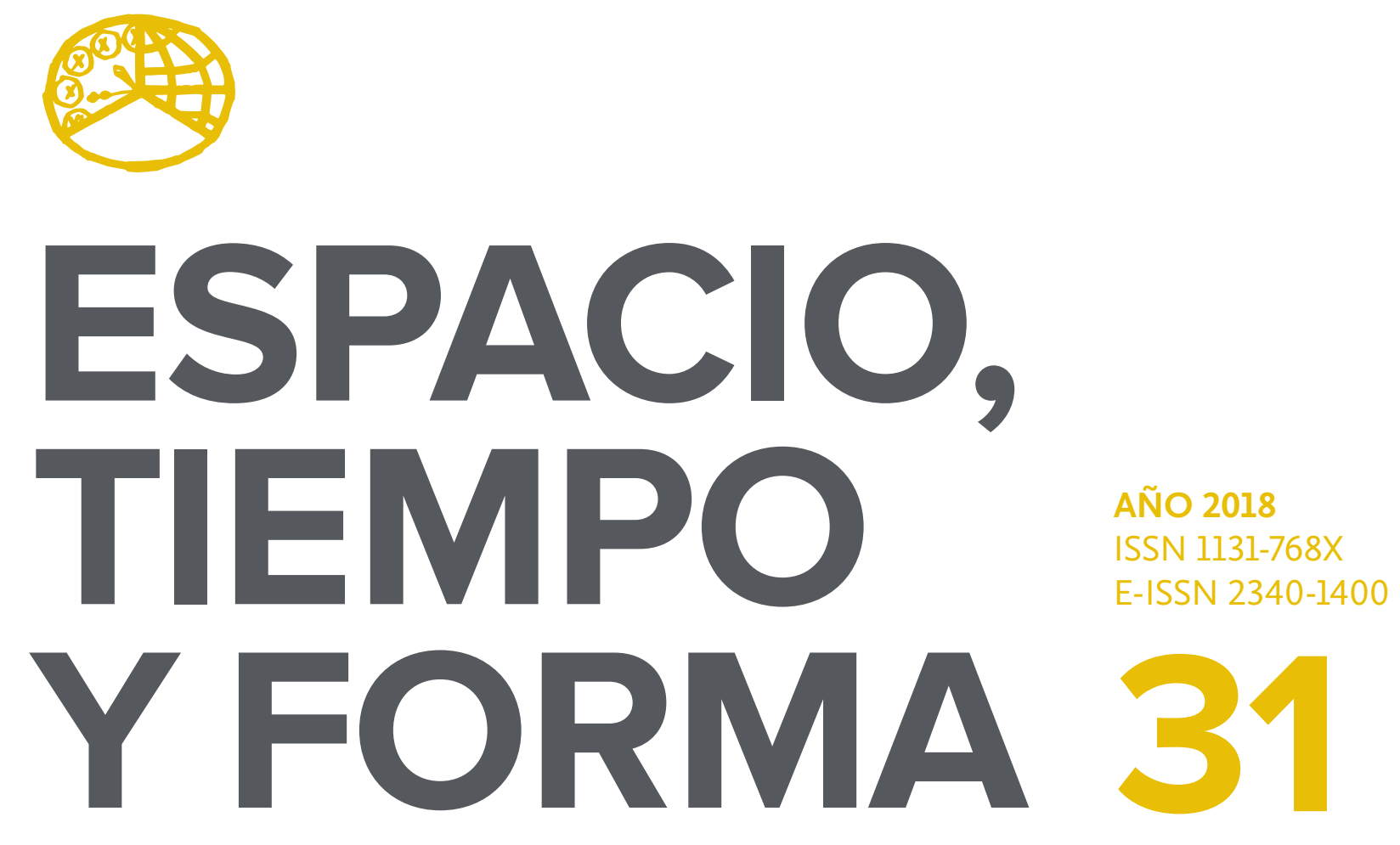

SERIE IV HISTORIA MODERNA

REVISTA DE LA FACULTAD DE GEOGRAFÍA E HISTORIA 


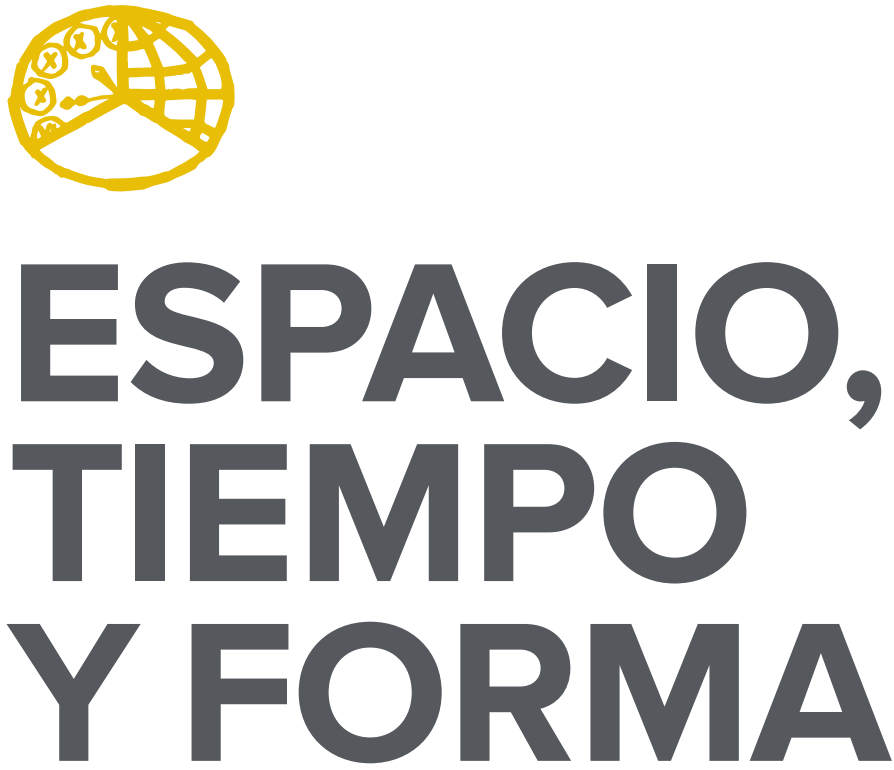

AÑO 2018

ISSN 1131-768X

E-ISSN 2340-1400

SERIE IV HISTORIA MODERNA

REVISTA DE LA FACULTAD DE GEOGRAFİA E HISTORIA

DOI: http://dx.doi.org/10.5944/etfiv.31.2018

\section{UกED}

UNIVERSIDAD NACIONAL DE EDUCACIÓN A DISTANCIA 
La revista Espacio, Tiempo y Forma (siglas recomendadas: ETF), de la Facultad de Geografía e Historia de la UNED, que inició su publicación el año 1988, está organizada de la siguiente forma:

$$
\begin{aligned}
& \text { SERIE I - Prehistoria y Arqueología } \\
& \text { SERIE II - Historia Antigua } \\
& \text { SERIE III - Historia Medieval } \\
& \text { SERIE IV - Historia Moderna } \\
& \text { SERIE V - Historia Contemporánea } \\
& \text { SERIE VI - Geografía } \\
& \text { SERIE VII - Historia del Arte }
\end{aligned}
$$

Excepcionalmente, algunos volúmenes del año 1988 atienden a la siguiente numeración:

$$
\begin{aligned}
& \mathrm{N}^{\circ} 1 \text { - Historia Contemporánea } \\
& \mathrm{N}^{\circ} 2 \text { - Historia del Arte } \\
& \mathrm{N}^{\circ} 3 \text { - Geografía } \\
& \mathrm{N} .^{\circ} 4 \text { - Historia Moderna }
\end{aligned}
$$

ETF no se solidariza necesariamente con las opiniones expresadas por los autores.

\author{
UNIVERSIDAD NACIONAL DE EDUCACIÓN A DISTANCIA \\ Madrid, 2018 \\ SERIE IV $\cdot$ HISTORIA MODERNA N. ${ }^{\circ} 31,2018$ \\ ISSN $1131-768 X \cdot$ E-ISSN 2340-1400 \\ DEPÓSITO LEGAL \\ M-21.037-1988 \\ URL \\ ETF IV · HISTORIA MODERNA · http://revistas.uned.es/index.php/ETFIV \\ DISEÑO Y COMPOSICIÓN \\ Carmen Chincoa Gallardo · http://www.lauridilva.net/cch \\ Impreso en España · Printed in Spain
}

(c) (1) (8) Esta obra está bajo una licencia Creative Commons Reconocimiento-NoComercial 4.0 Internacional. 


\section{MISCELÁNEA • MISCELLANY}





\title{
AL SERVICIO DE SU CATÓLICA MAJESTAD. LA CONCESIÓN DE MERCEDES DE LAS ÓRDENES MILITARES CASTELLANAS A MIEMBROS DEL CONSEJO DE ÓRDENES Y DEL CONSEJO DE CASTILLA EN EL REINADO DE FELIPE III (1598-1621)
}

\section{AT THE SERVICE OF HIS CATHOLIC MAJESTY. THE CONCESSION OF MERCEDES OF THE CASTILIAN MILITARY ORDERS TO MEMBERS OF THE COUNCIL OF ORDERS AND OF THE COUNCIL OF CASTILE IN THE REIGN OF FELIPE III (1598-1621)}

Héctor Linares González ${ }^{1}$

Recibido: 01/03/2018 - Aceptado: 04/09/2018

Doi: http://dx.doi.org/10.5944/etfiv.2018.21458

\begin{abstract}
Resumen
Las encomiendas de las órdenes militares castellanas constituían, junto con los bienes propios de la dignidad maestral, un extenso y rico conjunto patrimonial que estas milicias fueron adquiriendo de los reyes de Castilla y León en gratitud a los servicios prestados en la Reconquista. Con la incorporación perpetua de los Maestrazgos de las órdenes en la Corona de Castilla en 1523 se puso en manos de esta institución el derecho a dispensar las mercedes de las encomiendas, así como los títulos conferidos a estas milicias: los estatutos de caballero y comendador. Por ello, tras la incorporación, las encomiendas, dignidad del comendador, y los hábitos militares, como ya señaló la historiografía portuguesa para sus milicias (N. Monteiro y F. Olival) se integraron entre los mecanismos de remuneración de servicios de la Monarquía Católica. Desde esta perspectiva, este trabajo pretende el estudio de la concesión de encomiendas y hábitos de las tres órdenes militares de Castilla a miembros de los consejos de órdenes y Castilla en el reinado de Felipe III, intentando insertar estas mercedes dentro de la «economía de la merced» estableciendo, además, redes de parentelas y clientelas entorno a estas mercedes.
\end{abstract}

1. Universidad Autónoma de Madrid. C. e.: hector.linares@uam.es

Este trabajo se ha realizado en el marco del proyecto de investigación HAR2013-45788-C4-2-P, en el Instituto de Historia, CCHS, CSIC. Además, forma parte de la tesis doctoral «Encomiendas y Comendadores de las Órdenes Militares castellanas en el reinado de Felipe III, 1598-1621», desarrollada en el Departamento de Historia Moderna de la UAM. 
Palabras clave

Encomiendas; Órdenes Militares; Consejeros; Felipe III; Duque de Lerma.

\begin{abstract}
The commanderies of the Castilian military orders constituted an extensive and rich heritage set that these militias acquired from the kings of Castile and Leon in gratitude to the services rendered in the Reconquest. With the perpetual incorporation of the orders in the Crown of Castile, the right to dispense the commanderies was placed in the catholic monarchy, as well as the titles conferred to these militias: the statutes of knight and commander. For that reason, after the incorporation, the commanderies -dignity of the commander, and the military habits, as already indicated by the Portuguese historiography for their institutions (N. Monteiro and F. Olival)- were integrated between the mechanisms of remuneration of services to the Catholic Monarchy. From this perspective, this paper intends the study of the granting of encomiendas and habits of the three military orders of Castile to members of the Councils of Orders and Castile in the reign of Felipe III, trying to insert these mercedes within the «economía de la merced» establishment, in addition to the networks of relatives and clienteles around these mercedes.
\end{abstract}

Keywords

Commanderies; Military Orders; Counselors; Philiph III; Duke of Lerma. 


\section{CONSIDERACIONES PRELIMINARES. EL GOBIERNO POLISINODIAL Y LAS MERCEDES DE LAS ÓRDENES MILITARES CASTELLANAS}

Hablar de las órdenes militares es hablar de tradición histórica, de un legado de honor y privilegio nacido en la Edad Media, y que fue capaz de perdurar en el tiempo, sobrepasar los límites temporales de la reconquista, y llegar a la sociedad moderna como instituciones plenamente adaptadas a un nuevo orden y contexto. En efecto, estas instituciones en la Edad Moderna ${ }^{2}$ aún poseían una gran significación social, puesto que se presentaron en la España del Antiguo Régimen como organismos acreditadores del perfecto ideal del caballero cristiano, y de la más pura representación de la nobleza más generosa y loable 3 , que debía ser tomada como referencia en una sociedad que tenía a la aristocracia como espejo de príncipe. En su obra, Postigo Castellanos afirmaba que las órdenes militares quedaron en la sociedad moderna como organismos de discriminación social, cuyo fin último era «distinguir al noble del mecánico»4, constituyendo el Consejo de las Órdenes como un auténtico tribunal de honor y privilegios.

En este contexto, pertenecer a una orden militar suponía uno de los anhelos más ansiados no solo para la poderosa aristocracia, que vería así confirmada doblemente su nobleza (por el rey y Dios), sino también para los que la profesora Fernanda Olival ha denominado "grupos intermedios» ${ }^{6}$. Es decir, personajes que se encontraban entre la nobleza y las clases populares, y que se caracterizaban por servir al monarca desde puestos de gran responsabilidad sin tener un título nobiliario que avalase su condición social7 ${ }^{7}$. Conseguir un hábito militar, significaba, de facto, pertenecer a uno de los tres órdenes sociales, milites, los defensores de la sociedad, que poseían una posición preeminente por la misión de protección de los valores de la modernidad. Se entraba entonces en una comunidad de privilegio que se encontraba en la cúspide estamental. No es de extrañar entonces, como bien indican Domínguez Ortiz ${ }^{8}$ y Wright ${ }^{9}$, que en la España del Antiguo Régimen la petitoria de hábitos de las órdenes fuera enorme. Y sí para los hábitos la demanda era ingente, mayores deseos suscitaban las encomiendas, puesto que además de honor ser comendador aportaba riqueza ${ }^{\mathrm{IO}}$.

A partir de 1523 la administración de las órdenes militares correspondía a los soberanos de Castilla, gracias a la bula Dum Intra, lograda tras un intenso y arduo proceso de negociación entre España y la Santa Sede. El emperador Carlos conseguía

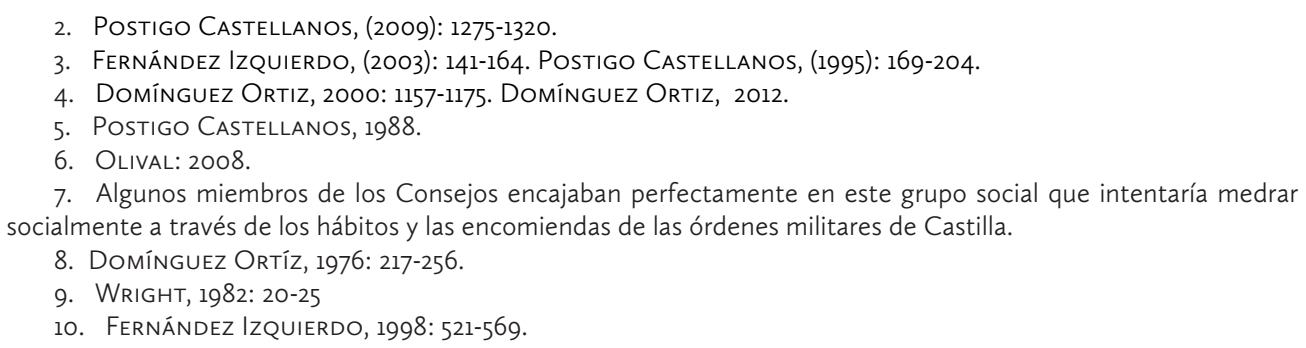


hacerse con estas instituciones de honor y riqueza ${ }^{\text {II }}$. A partir de este momento, el enorme y rico patrimonio del que con anterioridad disfrutaban los maestres pasó a manos de la Corona, así como los títulos conferidos a las milicias: los estatutos de caballero y comendador. De esta forma, estas mercedes empezaron a insertarse en el sistema de remuneración de servicios de la Monarquía Católica. En otras palabras, dentro de lo que la historiografía lusa denominó «economía de la gracia» ${ }^{12}$, recientemente ampliada a «economía de la merced» por Fernanda Olival ${ }^{13}$.

A partir del reinado de Carlos I se hizo necesario que la monarquía adquiera un aparato burocrático que la convierta en una entidad administrativa autónoma más allá de la figura de un rey que gobernaba sus territorios ${ }^{14}$. El régimen polisinodial fue el sistema por el que se institucionalizó la maquinaria burocrática. Es decir, el gobierno a través de diversos sínodos formados por un determinado número de miembros que despachaban los asuntos concernientes a cada consejo temático o territorial ${ }^{15}$. Estas instituciones representaban en la práctica la voluntad del soberano, que se expresaba y ejecutaba a través de órdenes delegadas. Los consejos elaboraban consultas que eran elevadas al monarca para que este pudiera tomar una decisión. Es por ello que en estos organismos la necesidad de los letrados era absoluta, y desde el reinado de los Reyes Católicos su importancia fue en aumento (sobre todo en los Consejos de Castilla, Aragón, y Órdenes) ${ }^{\mathrm{I}}$. Los consejos funcionaban como órganos colegiados presididos por un presidente elegido directamente por el rey, y que le aconsejaban en los asuntos concernientes al sínodo determinado. En la absoluta jerarquización de las instituciones se llegaba a advertir un cursus honorum dentro de los propios miembros de estos organismos, que iban promocionando desde ciertos consejos a los que se consideraban más importancias (con el Consejo de Castilla en la cúspide) ${ }^{17}$. Este se presentaba como el consejo real por tradición e historia, y disponía de amplias atribuciones en materia judicial y administrativa. El Consejo de Órdenes ${ }^{18}$, por su parte, se creó en 1523 tras la concesión de la administración perpetua de las órdenes militares castellanas a los reyes de España. Este se encargaba de la gestión y administración de todas las cuestiones relacionadas con las milicias castellanas. A partir de 1592 la Orden de Montesa pasará a ser administrada también por la corona. Sin embargo, su gestión nunca estuvo ligada al Consejo de Órdenes, sino al Consejo de Aragón ${ }^{19}$. Durante el siglo XVI, sobre todo durante el reinado de Carlos V y Felipe II, este régimen de gobierno mediante consejos estuvo protagonizado por los secretarios, personajes cercanos a la figura regia que en muchas ocasiones se convirtieron en los más cercanos colaboradores de los

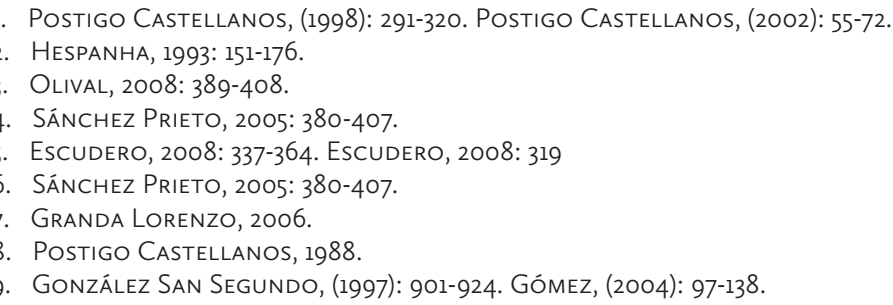


soberanos ${ }^{20}$. No obstante, tras la muerte del rey católico en 1598 esta primera etapa del gobierno de los consejos con preponderancia de los secretarios tocó su fin, entrando en escena los validos, ministros plenipotenciarios que encarnaron el poder regio, y funcionaban como el brazo ejecutor de las decisiones reales. Para Elliott el valimiento responde a un fenómeno de dimensiones europeas, que supuso el desbordamiento del sistema de gobierno por consejos, y la creación de una autoridad inmediatamente posterior al monarca que aun no poseyendo un nombramiento oficial, obtuvo poderes que incluso llegaban a superar a los de un primer ministro ${ }^{21}$.

Ante la importancia de estas instituciones, que constituían los máximos órganos de gobierno de la monarquía en el llamado sistema polisinodial, no es extraño observar cómo una gran cantidad de los miembros de los consejos pertenecían a una de las tres órdenes de caballería de Castilla, ya fuera como caballeros de hábito, o en el mejor de los casos, como comendadores o administradores de encomiendas. En este sentido, la concesión de mercedes de las órdenes se convirtió, en un momento en el que la Real Hacienda se encontraba cada vez más agotada por conflictos por medio mundo que la iban pauperizando día tras día, en una perfecta forma de remunerar servicios. Se sustituía, de esta forma, las mercedes pecuniarias por mercedes honoríficas, que en el gran teatro que era la España del seiscientos valían lo mismo o más. Unos años más tarde, en el reinado de Felipe IV, escribía Gaspar de Guzmán en su Gran Memorial un testimonio que lo confirmaba:

Sin castigo y premio no es posible conservarse las monarquías. Este se reduce a mercedes de hacienda y honra. Hacienda no la hay, con que ha sido justo y forzoso suplir esta falta con alargar las honras ${ }^{22}$.

Desde esta perspectiva, nuestro planteamiento inicial era realizar un estudio sobre la concesión de mercedes de hábito y encomienda de las Órdenes Militares de Castilla a los miembros de los consejos de la monarquía durante el reinado de Felipe III (I598-I62I). Sin embargo, al comprobar el enorme volumen de información y datos con el que trabajaríamos, y debido a las limitaciones del formato del proyecto, consideramos más viable acotar los parámetros de nuestra investigación. De esta forma, seleccionamos dos instituciones: el Consejo de Órdenes y el Consejo de Castilla ${ }^{23}$. Los miembros de ambos organismos, observados los casos de estudio, poseían grandes y continuas confluencias, siendo el Consejo de Castilla el destino de promoción de la mayoría de los miembros del Consejo de Órdenes, y éste a su vez el organismo del que se nutría la institución castellana. A través de las siguientes páginas intentaremos mostrar cómo una gran parte de los consejeros de estas dos instituciones fueron recompensados tanto con mercedes de hábito , así como de encomienda de las tres órdenes. De esta forma, podremos demostrar el uso del rico conjunto patrimonial de estas instituciones, y de los títulos conferidos a estas milicias, como forma de remuneración de servicios por parte de la Corona.

\footnotetext{
20. ESCUdERO LÓPEZ, 2009: 321-337.

21. ELLIOTT, 1999

22. Postigo Castellanos, 1988: 120.

23. BARRIOS, 2015
} 
Asimismo, prestaremos especial atención al papel que jugó el valido de Felipe III en este universo de la economía de la merced, observando que en muchos casos su influencia a la hora del nombramiento de cargos era absoluta. Encargándose, además, de monopolizar y canalizar la concesión de estas mercedes a sus más allegados colaboradores ${ }^{24}$. En anteriores estudios ya habíamos tratado la cuestión de la concesión de hábitos y, sobre todo, de encomiendas a las parentelas del valido durante el reinado de Felipe $\mathrm{III}^{25}$, pero conocer de qué forma eran premiados los miembros de los consejos de Órdenes y Castilla nos proporcionará una información muy valiosa acerca de este sistema de apropiación y uso interesado de las instituciones que caracterizó al gobierno de Lerma. Pues, como es evidente, estas dádivas no eran dadas sin motivo alguno, sino que de ellas se esperaba el cumplimiento de un servicio. Este, sin duda, para los miembros del Consejo de Órdenes ${ }^{26}$ sería seguir engrasando la gran maquinaria de concesión de mercedes de estas milicias a sus familiares y servidores, y para el caso de los consejeros de Castilla, temas políticos y administrativos referentes al gobierno de la monarquía.

\section{LA CONCESIÓN DE MERCEDES DE LAS ÓRDENES MILITARES A MIEMBROS DEL CONSEJO DE ÓRDENES Y CASTILLA EN EL REINADO DE FELIPE III (1598-1621)}

Entre 1598 y i6or Lerma comenzó a sustituir a los principales cargos de la monarquía por sus más fieles y cercanos servidores. Fueron muy pocos los ministros de Felipe II que consiguieron conservar sus cargos y dignidades en el nuevo reinado, puesto que la mayoría de las instituciones y cargos palaciegos comenzaron a ser ostentados por personajes de la talla de Calderón, Franqueza, o Ramírez de Prado. Tan solo unos meses después de la muerte de Felipe II empezaron a darse los primeros cambios en las instituciones de la monarquía. Algunos de ellos no tuvieron ningún tipo de repercusión, puesto que sus protagonistas fallecieron de forma natural tras ser apartados del poder. Entre ellos el presidente del Consejo de Castilla Ruy Vázquez de $\operatorname{Arce}^{27}$.

En 1599 se produjo la renovación de la presidencia del Consejo de las Órdenes. Tras cuatro años con Martín de Córdoba a la cabeza de la institución, el valido de Felipe III le reemplazó por Juan Idiáquez ${ }^{28}$. El noble vasco fue uno de los pocos ministros del anterior reinado que consiguió mantener sus cargos y honores en el nuevo gobierno. El duque de Lerma, sabedor de su amplia experiencia en los asuntos Estado y en los negocios de la monarquía, le ofreció el puesto, que aceptó rápidamente.

24. Gómez Rivero, (2003): 193-230.

25. LiNAREs GonZÁlez, 2018.

26. Pizarro Llorente, 2008: 300-303

27. Alvar Ezquerra, 2009: 132-133.

28. ARTOLA, 2000: 145 . 
Comprendió el duque que este hombre, aunque sabio, habría con facilidad acomodarse a servir a las mudanzas del tiempo, y no se engañó, porque le halló muy suyo y le importó mucho, para su conducta lo que ministraba Ydiáquez. ${ }^{29}$

De esta forma, se daba fin a la presidencia del marqués de Cortes, que abandonó la institución pero no así la encomienda que Felipe Il le había concedido en el año I595 tras acceder al Consejo, y que no era otra que la de Socuéllamos, que como apuntaremos se le dará al conde de Miranda tras la muerte del marqués ${ }^{30}$. El inicio de Idiáquez al frente del consejo vino acompañado de una renovación casi completa de los miembros de la institución. En estos momentos el Consejo de Órdenes estaba formado por un presidente, cuatro consejeros, un fiscal togado y otro de capa y espada, tres procuradores generales de capa y espada, un secretario, tres relatores, dos escribanos de cámara, y un solicitador fiscal ${ }^{31}$. Al final del reinado, sin embargo, el número de consejeros había aumentado a seis togados ${ }^{32}$. Estos eran nombrados por el soberano tras un trámite de elección, normalmente por ternas. En los consejos de Castilla y Órdenes los candidatos eran presentados a través de la Cámara de Castilla. Los consejeros, una vez nombrados, eran miembros a perpetuidad siempre y cuando el monarca decidiese lo contrario en base a una situación de gravedad ${ }^{33}$.

En el mismo año de 1599 dejaron de ser consejeros Gaspar de Bonifaz ${ }^{34}$, Francisco de Contreras, y Juan Ocón. El primero de ellos fue reemplazado por Álvaro de Benavides, familiar del duque de Lerma tras un matrimonio bien concertado con un miembro del linaje de la esposa de Sandoval. El consejero Benavides recibió poco después de su nombramiento un hábito de Santiago. En tan solo dos años, I602, promocionó al Consejo de Castilla. Sin embargo, pocas semanas después Bonifaz fue readmitido en el consejo como miembro supernumerario, gracias la intercesión de Martín de Córdoba ante el valido, que le presentó como un gran experto y conocedor del sistema de probanzas ${ }^{35}$. De esta forma, continuó en la institución hasta el año I603 en que abandonó de forma definitiva el consejo, aunque se llevó como compensación la encomienda santiaguista de Castilleja de la Cuesta (I.234 ducados/ año $)^{36}$ en I $604^{37}$. En el mismo año también se le concedió la tenencia de alcaidía de Higuera de la villa de Llerena ${ }^{38}$. Por su parte, el licenciado Juan de Ocón, que había accedido al Consejo de Órdenes en 1595 tras la promoción de Francisco de Albornoz ${ }^{39}$ al de Castilla, recibió de Felipe Il un hábito de Calatrava ${ }^{40}$, y tan solo unos meses después la encomienda del Tesoro de Calatrava (2.345 ducados/año), que mantuvo

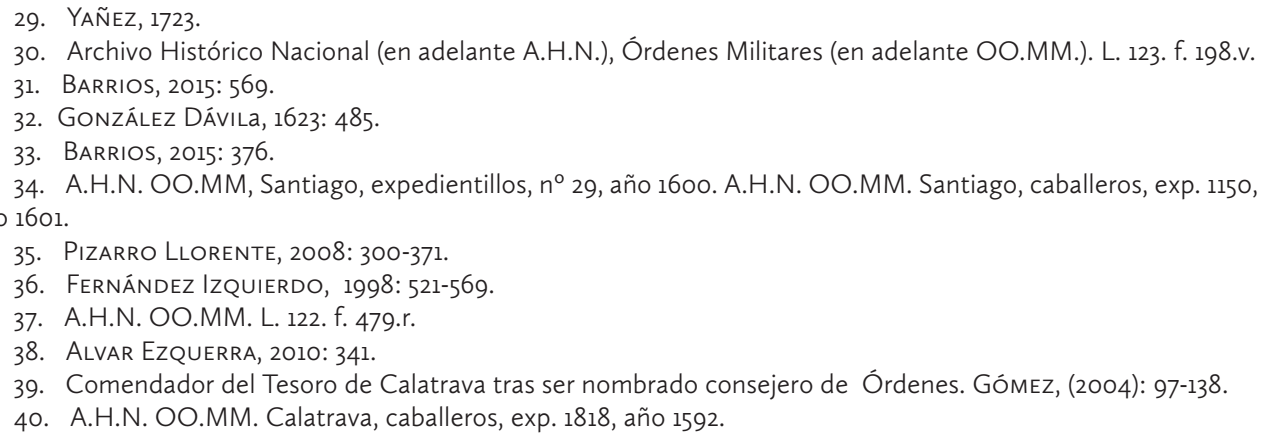


hasta su muerte ${ }^{41}$. En 1599, como el resto de sus compañeros, también abandonó el Consejo de Órdenes con destino a una magistratura superior ${ }^{42}$. Tras la partida de Juan de Ocón al Consejo de Indias, entró a formar parte del Consejo Antonio de Pedrosa ${ }^{43}$, anteriormente oidor en la Chancillería de Valladolid ${ }^{44}$. Tuvieron que pasar cinco años para que la Corona agradeciese los servicios del licenciado Pedrosa como consejero de órdenes. Así, en septiembre de I605 el soberano le hizo merced de la encomienda de Almagro, disfrutándola hasta el año I $625^{45}$. Un año más tarde, en septiembre de I606, volvió a recibir otra encomienda, la del Tesoro de Calatrava, y esta vez en administración, puesto que mantenía Almagro como encomienda titular ${ }^{46}$. No obstante, aún siendo beneficiario de dos ricas encomiendas de la orden, estas no fueron las últimas mercedes que el licenciado Pedrosa recibió de la Corona como forma de remuneración de servicios. A dos años de obtener la administración de la encomienda del Tesoro de Calatrava, el 8 de noviembre de i6o8, el soberano le concedió la encomienda del Moral (6.008 ducados/año) ${ }^{47}$.

Por último, Francisco de Contreras que comenzó su carrera en el Consejo de Órdenes en I59I, promocionó en I599 al Consejo de Castilla. Parece que su labor en esta institución fue, al igual que en los casos anteriores, del agrado del valido, puesto que en el año I606 se le concedió la administración de una de las encomiendas más ricas de Santiago ${ }^{48}$, la de Hornachos ( 5.333 ducados/año), que gestionó hasta que en r6o8 se le concedió al marqués de la Bañeza, hijo del conde de Miranda y presidente del Consejo de Castilla ${ }^{49}$. Pasado un lustro, Felipe III confirmó los buenos servicios de Contreras en el Consejo de Castilla otorgándole la encomienda de La Hinojosa (2.344 ducados/año) ${ }^{50}$. La última y gran dádiva de las órdenes que la monarquía concedió a Contreras sucedió en marzo de I625, con Felipe IV ya en el trono, y Contreras como presidente de Castilla, cuando se le hizo merced de una de las mayores dignidades de la Orden de Santiago, la encomienda Mayor de León (2.344 ducados/año) ${ }^{51}$. El único de los consejeros del periodo de Martín de Córdoba que mantuvo su plaza en el Consejo de Órdenes fue Juan de Alderete ${ }^{52}$, que inmediatamente después de entrar a formar parte de la institución se le concedió un hábito de Alcántara ${ }^{53}$, y pocos meses más tarde la encomienda de Hornos (I.345 ducados/año) ${ }^{54}$. No obstante, la carrera de Alderete no concluiría en este sínodo,

1. Cervera de la Torre, 1600: 202.

42. FERNÁNDEZ IZQUIERDO, 1992: 361.

43. Era caballero de Calatrava, pero en el año 1613 solicitó al monarca poder pasarse a Alcántara, como indican los expedientillos de la orden. A.H.N. OO.MM, Expedientillos, nº 962, año 1613.

44. Gómez, (2004): 657-744.

45. A.H.N. OO.MM. L. 203. f. 108. v.

46. A.H.N. OO.MM. L. 203. f. 140. r

47. A.H.N. OO.MM. L. 203. f. 269. r.

48. SalAzAR Y CASTRO, 1704: 631.

49. A.H.N. OO.MM. L. 124. f. 52.v.

50. A.H.N. Orden de Santiago, Registro del Sello, leg. 2556.

51. Que mantuvo de forma vitalicia hasta 1630. A.H.N. OO.MM. L. 127. f. 291.r. Ese mismo día se le concedió la encomienda de Hinojosa, vaca por promoción de Contreras, a Diego de la Vega.

52. Caballero de Santiago en 1626. A.H.N.OO.MM. Santiago, caballeros, exp. 256, año 1626

53. A.H.N. OO.MM. Alcántara, caballeros, exp. 53, año 1595.

54. Cervera de la TORre, 1600: 202-203. 
puesto que como algunos de sus compañeros, y gracias al favor que disfrutaba del valido, fue ascendido al Consejo de Castilla en $1604^{55}$. La presidencia de Idiáquez se inauguró, además de por la renovación de los miembros del consejo, también por una gran concesión de mercedes de encomienda de las tres órdenes. La cual tuvo como principales beneficiarios a miembros del Consejo de Castilla, además de los servidores de palacio:

Hanse proveído estos días pasados veinte encomiendas de las tres órdenes, aunque ninguna asa de 2.000 ducados de renta, y las más no llegan a 1.000, y se han dado a criados del Rey y del Consejo Real... ${ }^{56}$

Como vemos, durante la directorio del conde de Miranda, consuegro del duque de Lerma, varias personalidades cercanas al valido accedieron al Consejo de Casti1la. Entre I604 y I608 se dieron cinco nuevos nombramientos omitiendo el trámite de la consulta previa del Consejo de la Cámara ${ }^{57}$. Entre ellos estaban Ramírez de Arellano, Diego de Alderete, y Ramírez de Prado. El último de ellos había servido a Sandoval desde hacía años, pues dejó de servir a los duques de Feria para colaborar con el futuro valido, y tras su nombramiento como consejero de Castilla le llegó una merced de hábito santiaguista ${ }^{58}$. Por su parte, en enero de I6I5 se le concedió a Gil Ramírez de Arellano, familiar de Carlos de Arellano (hijo segundón del conde de Murillo y gran hechura de Lerma), la administración de la encomienda de Horcajo (I.234 ducados/año) tras la promoción de Alonso Idiáquez, duque de Ciudad Real, a la encomienda Mayor de León ${ }^{59}$. Disfrutó de los frutos de la encomienda durante dos años, hasta enero de I6I7, cuando Felipe IIl hizo merced de la encomienda de Horcajo al marqués de Aguilar ${ }^{60}$. El último de los tres consejeros que fue premiado con una merced de las órdenes militares por sus servicios como miembro del Consejo de Castilla fue Diego de Alderete, recibiendo un hábito de Santiago poco tiempo después de acceder al cargo ${ }^{61}$. En I6I5, el mismo día en que se le concedió la administración de la encomienda de Horcajo a Ramírez de Arellano, también se adjudicó a Diego de Alderete la administración de la encomienda de Dos Barrios ${ }^{62}$ cuyo valor ascendía, aproximadamente, a los I.300 ducados anuales ${ }^{63}$. Con anterioridad Alderete había ocupado puestos de responsabilidad en el Consejo de Indias, aunque era evidente que los tres personajes medraban tanto en las instituciones de la monarquía como en las órdenes militares gracias al gran favor de su patrón.

Tan solo unos meses antes del retiro del Conde de Miranda, el soberano hizo merced de la administración de la encomienda de Monreal ${ }^{64}$ a Álvaro de Benavides,

55. Pizarro Llorente, 2008: 300-371.

56. Cabrera de Córdoba, 1857: 168.

57. RIVERO, (2004): 97-138.

58. García De Villanueva, 1802: 291.

59. A.H.N. OO.MM. L.125. f. 130.r.

6o. Salazar y Castro, 1704: 254.

61. A.H.N. OO.MM. Santiago, Expedientillos, n² 211, año 1609.

62. A.H.N. OO.MM. L.125. f.130.r.

63. FERNÁNDEZ IZQUIERDO, 1998: 521-569.

64. A.H.N. OO.MM. L. 124. F. $74 . v$ 
pariente de Lerma. Fue precisamente en la misma jornada, el día 8 de noviembre de I608, cuando el monarca concedió la encomienda de Socuéllamos al marqués de la Bañeza, quien anteriormente había sido titular de la encomienda de Hornachos tras la promoción de Cristóbal de Sandoval a la de Caravaca ${ }^{65}$. Benavides disfrutó durante menos de un año las rentas de Monreal, dado que a los pocos meses le fue concedida la encomienda Mayor de Aragón de la Orden de Santiago ${ }^{66}$, valorada en 600 ducados anuales ${ }^{67}$. Quizás esta encomienda no se caracterizada por sus abultadas rentas, pero si por su enorme prestigio ${ }^{68}$.

En I608 el conde de Miranda dejó la presidencia del Consejo de Castilla vaca, por lo que Felipe III decidió nombrar para la dirección de la institución al mentor de Cristóbal de Sandoval, Juan de Acevedo (en ese momento inquisidor general). Sin embargo, su dirección solo abarcó tres meses, pues murió en el mismo año ${ }^{69}$. En su fulminante paso por la institución no dio tiempo a renovar plazas del consejo, pero tras su muerte, y mientras se elegía a un candidato para ocupar la magistratura, se nombró como consejero a Alonso Molina de Medrano, fiel colaborador del valido, quien no dudó en aprovechar el momento para colocar a su cliente ${ }^{70}$. Este caballero malagueño había ejercido como inquisidor en Zaragoza, además de ser uno de los fundadores de la cámara de Indias en I60I ${ }^{71}$. Tan solo un año después de ser nombrado consejero se le hizo merced de una encomienda de Santiago ${ }^{72}$, en concreto la de Villafranca, cuyo título le fue dado en mayo de $1609^{73}$. Con el fallecimiento de Bautista de Acevedo arribó al consejo Pedro Manso, accediendo a la presidencia gracias a su estrecha relación con Rodrigo Calderón ${ }^{74}$. El nombramiento de Manso resultó muy polémico en la corte, dado que carecía de la experiencia y el prestigio de su antecesor, y era bien sabido que su carrera administrativa se debía íntegramente al favor del valido: «ha causado admiración a todos por haber subido en menos de dos años de alcalde de corte a presidente de Castilla»75. Tras acceder al cargo se nombró rápidamente como consejeros a Melchor de Teves y Martín Fernández ${ }^{76}$, aunque, extrañamente, no recibieron merced alguna de las órdenes militares durante su paso por la institución. Pocos meses después, en mayo, tras la vacancia del licenciado Medrano, se nombró como consejero a Luis de Padilla ${ }^{77}$. Por otro lado, a finales del año i6o9 se le concedió plaza de consejero de Castilla a un amigo del duque de Lerma, Luis de Salcedo, consejero de Indias, tras la promoción

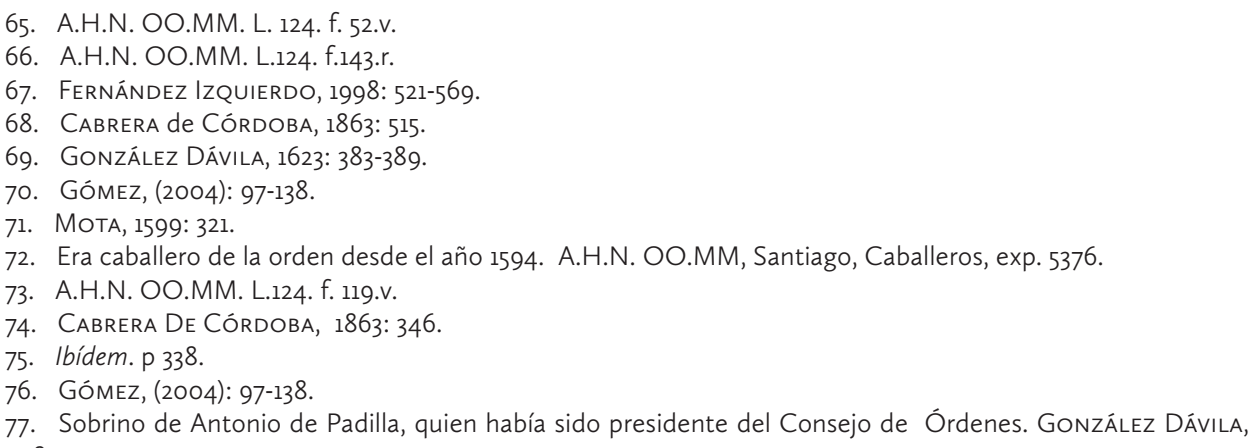


de Fernando Carrillo a la presidencia del Consejo de Hacienda ${ }^{78}$, que obtuvo tras su nombramiento un hábito de Alcántara ${ }^{79}$.

Paralelamente, en el Consejo de las Órdenes cuya presidencia se encontraba en la figura de Juan Idiáquez, se dieron nuevos ceses y nombramientos. En el mismo año de 1599 es elegido consejero Egas Venegas Girón, oidor en la Audiencia de Valladolid, e inmediatamente agraciado con un caballerato de Santiago ${ }^{80}$. Tras tres años como consejero, el soberano le concedió en administración las encomiendas santiaguistas de Alange y Lobón ${ }^{81}$. Un año después de su acceso a la presidencia, en i6oo, se nombró como consejero al licenciado García de Medrano, caballero de Santiago, y dos años después de entrar a formar parte del consejo recibió la administración de la encomienda de Reina (I.I23 ducados/año) ${ }^{82}$. La encomienda permaneció gestionada por García de Medrano durante cinco años, hasta que en el año i6o7 el soberano le concedió la encomienda al marqués de Flores Dávila, y consejero de guerra, Antonio de la Cueva ${ }^{83}$. Mientras administraba la encomienda de Reina Medrano publicó en Valladolid la Regla y Establecimiento de la Orden de Santiago de $1603^{84}$. Tanto el monarca como el valido tuvieron que estar muy satisfechos con el trabajo realizado por este caballero dado que tan solo unos meses después de la publicación de la célebre obra, en I604, fue promovido al Consejo de Castilla.

A la baja de García de Medrano se le sumaron tres más, la de Juan de Alderete ${ }^{85}$ por promoción al mismo consejo, y las otras dos restantes por fallecimiento. De esta forma, en $\mathrm{I} 604$ se hizo necesario volver a renovar el consejo, y en esta ocasión entraron a formar parte del organismo: Ruy Díaz de Mendoza, Luis de Padilla, Jerónimo de Medinilla, y Diego López de Salcedo ${ }^{86}$. Inmediatamente después de su nombramiento el soberano les hizo merced de un hábito de Santiago a cada uno de ellos ${ }^{87}$. Sin embargo, tan solo dos tuvieron el privilegio de disfrutar de las rentas de las encomiendas de Santiago. El que mayores beneficios obtuvo de ellas fue, sin duda, Jerónimo de Medinilla, quien en I605 recibió en administración la encomienda de Valencia del Ventoso, valorada en casi 4.000 ducados, que mantuvo hasta $1607^{88}$. Dos años más tarde, en I6o9 se le adjudicó, tras la muerte de Pedro Portocarrero, la administración de la encomienda de las Casas de Córdoba (3.60o ducs/año) ${ }^{89}$, que gestionó hasta que Felipe IIl concedió la encomienda a Hernando de la Cerda, del Consejo de Guerra ${ }^{90}$, y cuñado del valido. En abril de i6ı obtiene la administración de otra encomienda, la de La Membrilla (3.753 ducs/año). En

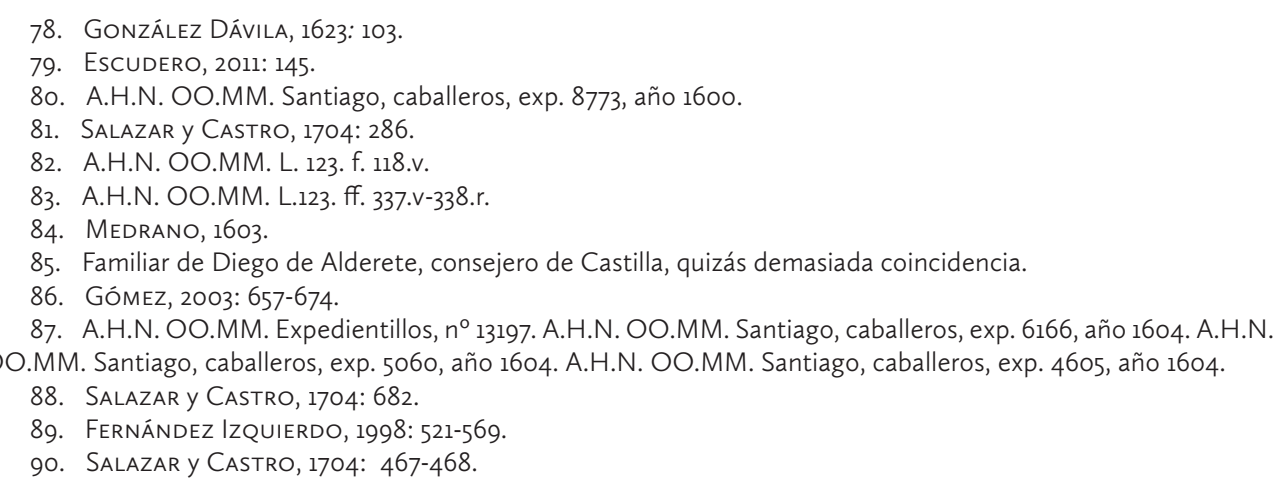


esta encomienda su presencia solo duró siete meses, hasta que el monarca otorgó la encomienda a Iñigo de Borja, también del Consejo de Guerra ${ }^{91}$, y familiar del Sandoval. Hasta en otras dos ocasiones más a Medinilla se le dio el encargo de administrar encomiendas santiaguistas. Entre julio de I6Io y marzo de I62I recibe la gestión de Sócobos ${ }^{92}$ (3.653 ducs/año), y desde febrero de I620 hasta marzo de I62I la de Usagre (I.345 ducs/año) ${ }^{93}$. Por su parte, el licenciado Salcedo también tuvo el privilegio de acceder a las riquezas de las encomiendas, puesto que en enero de I6I $5^{94}$ se le concedió la encomienda de Palomas (I.457 ducs/año) ${ }^{95}$. Con anterioridad había sido administrador de la encomienda de Lobón ${ }^{96}$ (en I605, tras pocos meses de ser nombrado consejero) y de Villamayor en el año $\mathrm{I}^{6} \mathrm{IO}^{97}$, disfrutando de sus rentas durante varios años. Por si fuera poco, el Consejo también brindó cargos a los familiares directos del licenciado Medinilla, puesto que al menos uno de sus hijos accedió a la gobernación del Campo de Montiel durante su etapa de consejero ${ }^{98}$.

En el año I6o6, el canónigo Enrique de Pimentel, hijo del conde Juan Alonso Pimentel, accedió al Consejo de las Órdenes como consejero" ${ }^{99}$. Seguidamente se iniciaron los trámites para concederle un hábito militar, en este caso, de la Orden de Alcántara, el cual le fue concedido en $1606^{100}$. Tras dos años como consejero, sus funciones fueron agradecidas por el soberano de Castilla a través de la encomienda alcantarina de Benfayan ${ }^{\text {Ior }}$, valorada en aproximadamente 2.600 ducados ${ }^{\text {I02 }}$. A estas rentas recibidas como comendador se le debían sumar, además, las que cobraba como administrador de la encomienda calatrava de Fresneda desde diciembre de $1608^{103}$. Fue en el mismo año de estas mercedes al consejero Pimentel cuando el Consejo de las Órdenes volvió a renovar las plazas de la institución. En esta ocasión el beneficiado fue el licenciado Pedro de Vega, que proveniente de la Chancillería de Valladolid ingresaba al consejo tras la muerte del consejero Venegas ${ }^{104}$. Días después de acceder a la institución comenzó el proceso de concesión de un hábito de

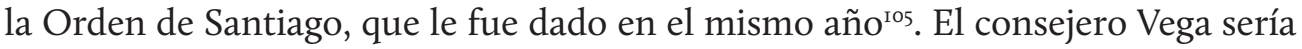
agraciado con la administración de una encomienda más de diez años después de acceder a la institución. En I62I, tras la ejecución de Rodrigo Calderón, Felipe IV le encargó la gestión de la encomienda de Ocaña ${ }^{106}$.

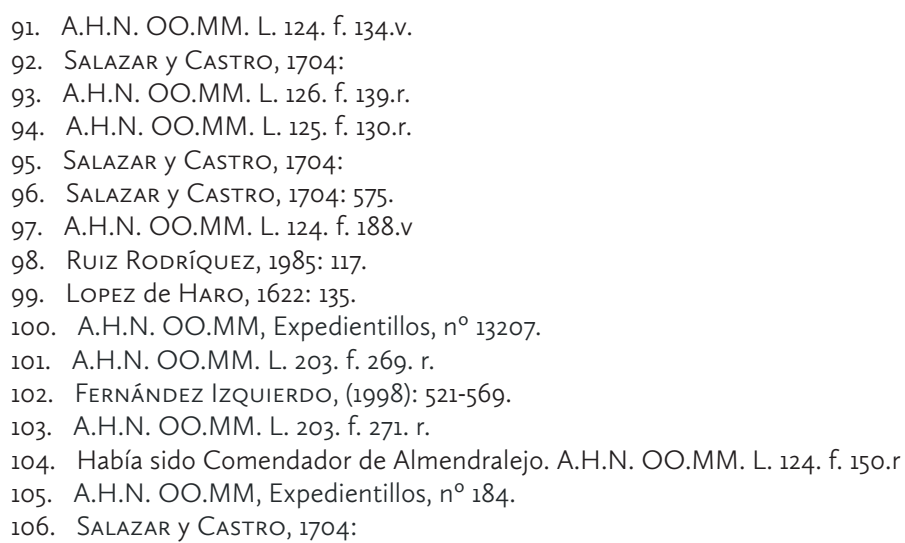


En el año I609, y tras tres años como consejero de órdenes, se produce la promoción del licenciado Padilla al Consejo real de Castilla, dejando su plaza vacante $^{\mathrm{I07}}$. A la sazón el elegido por el soberano será el licenciado Serrano Zapata, que curiosamente era sobrino del conde de Barajas, anterior presidente del Consejo de Castilla. Este nuevo nombramiento parece fruto de la estrecha relación existente entre el conde y el valido de Felipe III. Deberíamos pensar incluso si la promoción de Padilla al Consejo de Castilla no tuvo como motivo la concesión de la plaza que dejaría vacante al sobrino del expresidente de Castilla. Es cierto también que Zapata llevaba formando parte de la institución desde el año i6o4 cuando fue nombrado fiscal del consejo. Desde ese mismo año disfrutaba, además, de la venera de Calatrava ${ }^{108}$. Por otro lado, conocemos que durante el reinado de Felipe III se tuvo cierta tendencia a promocionar a los fiscales del consejo de las órdenes a los puestos de consejero ${ }^{\mathrm{rog}}$, por lo que fueron estos dos factores los que caracterizaron su promoción. Tras acceder a la plaza, y como empezaba a ser común en los consejeros de órdenes, el soberano le hizo merced de una encomienda. En este caso fue la encomienda de Batundera y juro por Badajoz, que recibió en septiembre de $1605^{\text {IIO }}$. Sin embargo, no accedió a la encomienda como comendador «colado», es decir, a través de la forma tradicional y recogida en los Establecimientos y Definiciones de las instituciones, sino mediante la fórmula de la administración con «goce de frutos». Esto se debía a que el licenciado Zapata era caballero calatravo, y la encomienda que le fue concedida era alcantarina. Para ello fue necesario pedir una autorización pontificia que le fue dada en el mismo año. Cinco años después, la labor de Zapata volvía a ser recompensada por la Corona en forma de otra encomienda, puesto que el I5 de marzo de i6ıo recibió la administración de la encomienda de Villasbuenas, en Alcántara, que disfrutó más de tres años ${ }^{\text {III }}$. Durante su etapa como consejero de órdenes recibió, además, otras tres encomiendas en administración en distintos momentos de su magistratura. Cobrando en todo momento, por supuesto, sus emolumentos por el trabajo realizado (Encomienda de Diezmos ${ }^{\mathrm{II} 2}$, encomienda Quintana ${ }^{\mathrm{II}}$, y la encomienda de Galizuela).

El linaje de los Zapata encontró acomodo en el consejo, dado que más de uno de sus miembros fue consejero de órdenes durante el siglo XVII, y no solo eso, sino que su familia tuvo el privilegio de poseer un gran número de encomiendas. Entre ellas encontramos las de Fuente del Emperador; Jimena, las Casas de Calatrava (Calatrava); Convento Viejo; Adelfa (Alcántara); y Montealegre (Santiago) ${ }^{\text {II4. Un }}$ ejemplo es el consejero Hernando Zapata, el cual sustituyó en la encomienda de Los Hornos de Alcántara al también consejero de órdenes Alderete tras su

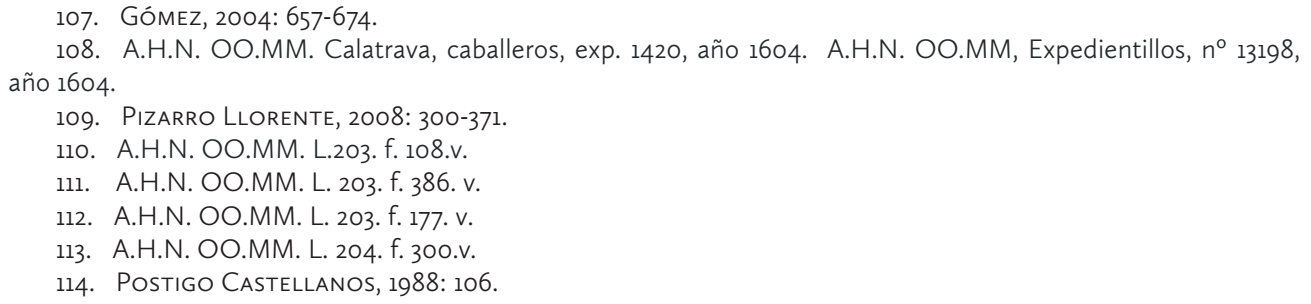




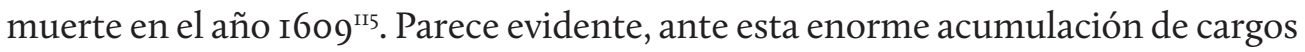
y oficios de estas instituciones, no solo que el valido se sentía complacido con las tareas realizadas por el linaje de los Zapata, sino que sus servicios estaban siendo remunerados a través de las mercedes de las órdenes.

Simultáneamente a la concesión de la plaza del Consejo de Órdenes a Serrano Zapata, el licenciado Francisco González de Heredia fue nombrado secretario de la institución. Desde el año I6oz llevaba siendo caballero profeso de Alcántara, cuando recibió dicha merced por los buenos servicios realizados en el cargo de secretario del rey ${ }^{\mathrm{II}}$. A partir de $\mathrm{i} 609$, y coincidiendo con su nuevo puesto de secretario del consejo, empezó a ser colmado de mercedes de las órdenes. En un primer momento se le concedió una encomienda alcantarina, la de la puebla ${ }^{117}$. El documento de concesión de la merced es una extensa Real Cédula (de casi diez caras) en la que el soberano agradece los buenos servicios realizados por González de Heredia al frente de la secretaría del consejo ${ }^{\text {II8 }}$. Tras ello, y una vez obtenida la dignidad de «comendador» de una orden, la institución comenzó a asignarle la administración de una gran cantidad de encomiendas, que le reportaban una suculenta suma año tras año ${ }^{\text {II9 }}$.

En el mismo I6I2 se eligió como fiscal del Consejo de Órdenes a Alonso de Cabrera, proveniente de la Real Chancillería de Valladolid, institución que presidía su tío paterno, y donde había ejercido como oidor ${ }^{120}$. Cinco meses después de su nombramiento como fiscal, y siguiendo la norma no escrita de promoción de los fiscales de órdenes a las plazas de consejero, Felipe III concedió la plaza vacante del consejero López de Ayala, quien promocionaba al Consejo real de Castilla, al licenciado Cabrera. Inmediatamente se iniciaron las diligencias para la concesión de un hábito de Calatrava a don Alonso ${ }^{121}$. Ya como caballero profeso se le adjudicó , en el mismo año, la administración de la encomienda calatrava de Peraleda ${ }^{\text {I22 }}$.

Por su parte, y tras casi una década como miembros del Consejo de las Órdenes, los licenciados Enrique Pimentel y Pedro Vega fueron ascendidos a otras magistraturas. El primero de ellos accedió a una plaza del Consejo de la Suprema Inquisición, y el segundo, a la presidencia de la Real Chancillería de Valladolid. Esto provocó dos vacantes en el consejo, más la secretaría del consejo, que quedó vaca tras la muerte del licenciado González de Heredia ${ }^{123}$, por lo que se dieron dos nuevas consultas en agosto de I6I3. En ese mismo año, además, el soberano había promocionado al caballero Antonio Pimentel a la encomienda calatrava de Belvis de la Sierra, dejando vaca la encomienda del Castillo, de la que era titular hasta ese momento $^{124}$. Curiosamente, esta encomienda fue concedida en administración a

\footnotetext{
115. A.H.N. OO.MM. L. 203. f. 25.r.

116. A.H.N. OO.MM. Caballeros, Alcántara, exp. 641, año 1602.

117. Álvarez-Coca GonzÁlez, 1994: 297-323.

118. A.H.N. OO.MM. L. 203. ff. 318.v-325.r.

119. A.H.N. OO.MM. L. 203. f. 385.v.

120. GómeZ, (2004): 660

121. A.H.N. OO.MM, Calatrava, caballeros, exp. 383, año 1612.

122. A.H.N. OO.MM. L. 203. f. 30.r.

123. A.H.N. OO.MM. L. 204. f. 128.v.

124. A.H.N. OO.MM, L. 204. f. 88. v
} 
su primo el consejero Enrique Pimentel, que disfrutó de las rentas de la misma durante varios años ${ }^{125}$. Por la cronología en la que se promocionó a Antonio Pimentel de encomienda, y la coyuntura profesional que atravesaba el consejero don Enrique, promocionando también a otro consejo (más elevado) de la monarquía, podemos intuir que esta concesión de administración (que siguió conservando aún siendo consejero de Castilla) estuvo ligada a una remuneración de servicios por parte del monarca por tantos años de buen servicio en el Consejo de Órdenes. No obstante, Antonio Pimentel no fue el único familiar del consejero que disfrutó de los honores y riquezas de las encomiendas dado que, en el mismo año de I6I3, el soberano también otorgó otra encomienda a un hermano del consejero, a Alonso Pimentel, que accedió al señorío calatravo de Montachuelo ${ }^{126}$, valorado en más de I.400 ducados anuales ${ }^{127}$, tras la muerte de su titular. Como vemos, el linaje de los Pimentel, obtuvo amplias mercedes de estas instituciones durante el reinado de Felipe III, gracias sin duda, a la influencia del poderoso Sandoval, de quienes eran palpablemente cercanos ${ }^{128}$.

Por lo que se refiere a las plazas vacas resultantes de la promoción de los mencionados, se presentaron seis candidatos, y de entre estos fueron elegidos para las plazas el fiscal del Consejo de Órdenes, Pedro de Álava, y el oidor de Valladolid, Juan Gaitán de Ayala ${ }^{\text {I2 }}$. El mismo día en que se resolvieron las vacantes comenzó el proceso de concesión de un hábito a los dos nuevos consejeros. A Pedro de Álava se le concedió en Santiago ${ }^{\mathrm{I3} 0}$, por su parte, Gaitán lo obtuvo en Alcántara ${ }^{13 \mathrm{I}}$. No hubo demasiado tiempo para que la Corona y el valido agradeciesen los servicios prestados por Álava, dado que meses después de haber recibido el hábito falleció en Madrid, dejando vacante su plaza. La elección de esta plaza, como indica Gómez Rivero $^{\mathrm{I} 32}$, implicó que Lerma interviniese de forma directa en el nombramiento del nuevo consejero. De esta forma, recomendó al licenciado Chaves para el puesto, algo que el presidente del consejo de Órdenes, Juan de Idiáquez, que debía bastantes favores al valido, seguramente hubiese acatado. No obstante, en esta ocasión el soberano decidió que la plaza fuese para Coello de Contreras, y que Chaves fuese promovido a alcalde de corte. Sin duda, a finales de I6I4 las intrigas, y la enorme oposición al valido, junto con el proceso a cercanos colaboradores de Lerma (Franqueza y Arellano) empezaban a hacer mella en la confianza que el soberano había depositado en el valido. Al nuevo consejero se le concedió un hábito santiaguista meses después de su entrada en la institución ${ }^{133}$, tras concluir correctamente las

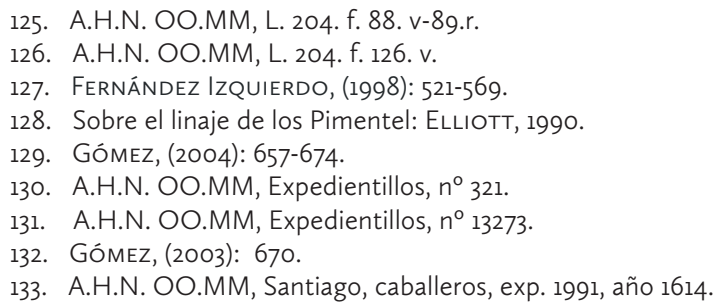


probanzas realizadas por el consejo a través de las informaciones recabadas por García Bravo de Acuña y Alfonso Vadillo ${ }^{\mathrm{I3} 4}$.

En I6I5 Juan de Idiáquez abandonó la presidencia del Consejo de Órdenes, siendo sucedido por Luis Carrillo de Toledo, que desde el año I59o profesaba un hábito de Santiago ${ }^{135}$. El marqués de Caracena debía la mayoría de sus logros al valido, quien en I606 le consiguió tal marquesado, y poco tiempo más tarde la encomienda de Montizón y Chiclana ${ }^{136}$ (3.229 ducs/año). Entre I6I6 y I62I el Consejo de Órdenes designará otros cuatro nuevos consejeros. De estos nombramientos, dos se produjeron tras las promociones de Alonso de Cabrera al Consejo de Castilla y Juan Gaitán de Ayala al Consejo de la Suprema. La primera de las plazas fue ocupada por Luis de Villavicencio ${ }^{137}$, y la segunda por Pedro de Guzmán ${ }^{138}$. Las otras dos restantes serán ocupadas por Juan Jiménez de Oco, caballero de Santiago ${ }^{\mathrm{I} 39}$, y por Sebastián de Villafañ ${ }^{140}$, que morirá si haber tomado posesión de su plaza. A este respecto, es nombrado para sustituirle en la plaza Juan Chumacero, que ejercía de fiscal del consejo desde $\mathrm{I}_{62} \mathrm{O}^{\mathrm{I} 4 \mathrm{I}}$. El consejero Jiménez de Oco llegará a administrar hasta tres encomiendas de la Orden de Santiago durante su magistratura: Estepa ${ }^{\mathrm{T} 42}$, Montiel ${ }^{\mathrm{I} 33}$ y Socobos ${ }^{144}$. Tras el ingreso en la institución, los nuevos miembros recibieron casi de forma inmediata un hábito militar. Pedro de Guzmán profesó en Calatrava ${ }^{145}$, y a Luis de Villavicencio, por su parte, se le hizo merced de un hábito alcantarino ${ }^{\mathrm{I} 46}$. Este último tuvo que esperar casi cinco años para conseguir una encomienda de la orden, pero el momento llegó tras la muerte de Jerónimo Zapata. Tras lo cual, Felipe III concedió la encomienda de los Hornos en administración al licenciado Villavicencio ${ }^{\mathrm{I4} 7}$. Por último, Juan Chumacero de Sotomayor recibió un hábito de Santiago en el año $162 \mathrm{O}^{\mathrm{I} 48}$, y tras unos años en la institución fue promocionado, como la mayoría de sus compañeros, al Consejo de Castilla ${ }^{149}$, que llegaría a presidir durante el gobierno del conde-duque de Olivares.

Por su parte, en el Consejo de Castilla, institución a la que promocionaban principalmente, junto al Consejo de la Suprema, los consejeros de órdenes, también se dieron dinámicas similares en la segunda mitad del reinado del tercer Felipe. La presidencia de la institución se renovó en el año i6ıo, cuando Pedro Manso dejó el cargo, y se produjo uno de las primeros enfrentamientos entre la facción opositora

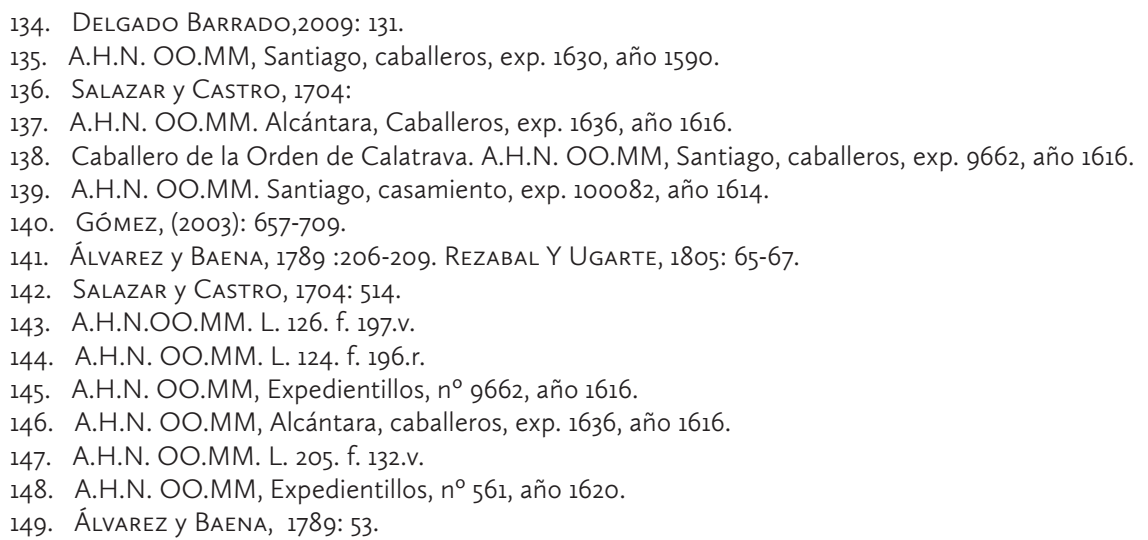


y el propio valido. Lerma propuso como candidato a la magistratura a un familiar de la esposa de Calderón, Gabriel de Trejo, también consejero de Órdenes. El confesor Aliaga y el duque de Uceda, sin embargo, apostaban por Juan de Acuña. Felipe III sorprendentemente se decantó por el candidato del confesor, causando la primera gran derrota del valido ${ }^{150}$. Lerma perdía, de esta forma, el control del consejo más importante de la monarquía. La relación entre Acuña y el primer ministro, además, no fue demasiado buena. De hecho, el nuevo presidente llegó a negarle una investigación contra Aliaga, y ante tal negativa, el valido tuvo que pedir a Felipe III lo que hoy conocemos como la «delegación de firma». Por lo que se refiere al propio Acuña y su relación con las órdenes, hemos de decir que no solo era caballero santiaguista ${ }^{151}$, sino que además fue comendador en la misma institución ${ }^{152}$. La buena relación con Aliaga y Uceda, así como sus servicios al frente del Consejo no solo se tradujeron en su título de marqués ${ }^{153}$ y su propio hábito y encomienda, sino que el monarca también le concedió lo mismo a su primogénito. Diego Melchor de Acuña recibió un hábito santiaguista poco antes de entrar su padre a la presidencia de la institución $^{154}$. Tras ello, en el año I62I se le hizo merced de la encomienda de Usagre ${ }^{155}$.

De entre los nuevos consejeros que arribaron al consejo de Castilla entre i6ro y I6I5, es decir, durante el tiempo que duró la presidencia de Acuña, dos lo hacían promocionando desde el Consejo de Órdenes, de los que ya dimos cuenta en las páginas anteriores, y que fueron premiados con hábitos y encomiendas de las órdenes (Gerónimo de Medinilla y Diego López Salcedo). En I6I3 entró también a formar parte de la institución el hasta entonces fiscal del Consejo de Indias Hernando de Villagómez ${ }^{156}$. Los tres últimos nombramientos dados antes del término de la presidencia de Acuña fueron los de Juan de Frías, Gabriel de Trejo, y Márquez de Gaceta. El primero fue miembro de la Contaduría Mayor de Hacienda, el segundo consejero de la Suprema ${ }^{157}$, y el tercero oidor en la Audiencia de Valladolid (llegaría presidir la Chancillería de Valladolid). Los dos primeros accedían al consejo tras el fallecimiento de Luis de Padilla, y el retiro de Francisco de Contreras, anteriores consejeros de órdenes. Trejo, por su parte, había servido como fiscal del Consejo de Órdenes desde I6o8, y tras unos años en la institución fue promocionado al Con-

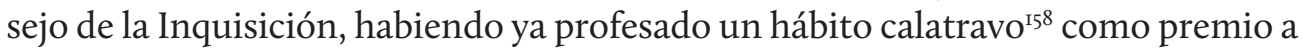
sus múltiples servicios, y gracias a ser familiar de Rodrigo Calderón ${ }^{159}$.

En septiembre de I6I5 fallece Juan de Acuña, dejando vacante la más alta magistratura de la institución. El rey eligió para sucederle al arzobispo de Burgos, Fernando de Acevedo, caballero de Santiago desde el año $1592^{160}$. El religioso accedía

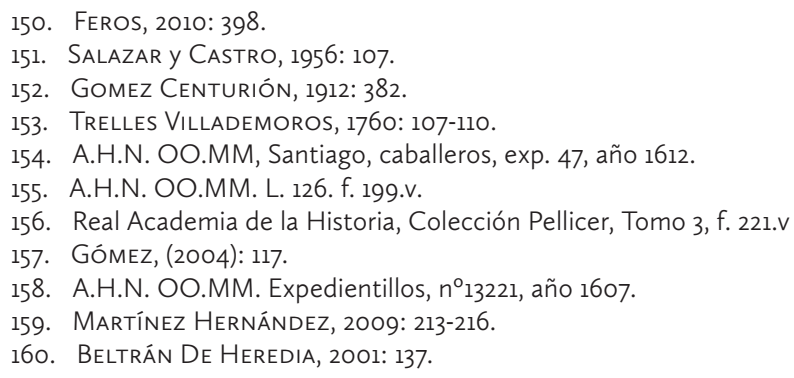


la institución gracias a la buena relación que poseía con el secretario Mateo Vázquez y el capellán Loysa ${ }^{161}$, y sobre todo, en virtud a la influencia del confesor y el duque de Uceda, quienes llegaron a convencer a Felipe III de su idoneidad para el cargo. Su elección supuso, como bien indica A. Feros, una auténtica derrota para el valido, y el segundo gran triunfo de su facción rival, que conseguía acabar completamente con el dominio de Lerma sobre el Consejo de Castilla ${ }^{\mathrm{I} 62}$. Durante el mandato de Acevedo, el último del reinado de Felipe III, se dieron doce nombramientos de consejeros de Castilla, varios de ellos supernumerarios. Pues bien, de los doce nuevos miembros, diez consiguieron un hábito de las órdenes castellanas tras acceder a la institución. En el año I6I6 se dieron las primeras concesiones de la presidencia de Acevedo, y una de las mismas fue concedida al licenciado Alonso de Cabrera, que arribaba al consejo procedente del de órdenes, y a quien se le hizo merced de la encomienda de Bejis tan solo unos meses después ${ }^{163}$. En el mismo año se resolvieron cuatro nuevas plazas ${ }^{164}$. La primera fue dada a Gilmón de la Mota, que desde I6I2 llevaba ejerciendo como fiscal del mismo consejo, y por tales servicios fue recompensado con un hábito de Santiago ${ }^{165}$. Los otros tres consejeros que entraron a formar parte del organismo en el año i6ı6 fueron Fernando Ramírez de Fariña, Gaspar Vallejo, y Juan Chaves y Mendoza, conde de la Calzada. A este último se le procuró un hábito de Santiago ${ }^{\mathrm{r} 66}$ pocos meses antes de morir Felipe III. Gaspar de Vallejo, por su parte, también fue agraciado con un hábito del apóstol dos años más $\operatorname{tarde}^{\mathrm{I} 67}$. A Ramírez de Fariña se le hizo merced, además, de la encomienda santiaguista de Torres, aunque su concesión se realizó en el reinado de Felipe IV (I639) ${ }^{168}$.

En el último periodo de la presidencia de Acevedo, entre I6I8 y I62I, se dieron nuevas bajas y nombramientos. Fue propuesto y seleccionado el licenciado Diego del Corral, a quien se le concedió un hábito de Santiago en el mismo año de I6I ${ }^{169}$, junto a sus compañeros Pérez de Araciel ${ }^{170}$ y Juan de Villela ${ }^{171}$, también nombrados caballeros de Santiago en esas fechas. El consejero Villela llegaría a ser nombrado Comendador Mayor de Aragón en la Orden de Santiago en el año I628, justo al ser promocionado al Consejo de Indias en calidad de Presidente ${ }^{172}$. Los dos últimos consejeros, Francisco de Tejada ${ }^{173}$ y López Madera ${ }^{174}$ recibieron, asimismo, ambos hábitos de Santiago. Aunque Francisco de Tejada nunca llegaría a ser titular de una encomienda de la orden, si que disfrutó de tal privilegio su hijo mayor, Fernando Miguel, cuando en i675 Carlos Il le hizo merced de la administración de la encomienda

\footnotetext{
161. GonZÁlez DÁVILA, 1623: 383-389.

162. Feros, 2010: 399-401.

163. A.H.N. OO.MM. L. 203. f. 218. r.

164. GómeZ, (2004): 128-129.

165. A.H.N. OO.MM, Expedientillos, $n^{\circ} 756,1612$. Santiago

166. A.H.N. OO.MM, Santiago, caballeros, exp. 2332, año 1621

167. A.H.N. OO.MM, Santiago, caballeros, exp. 8507, año 1618.

168. Salazar y CASTRO, 1704: 328.

169. A.H.N. OO.MM, Santiago, caballeros, exp. 2145, año 1621.

170. A.H.N. OO.MM, Santiago, Caballeros, exp. 6352, año 1622

171. A.H.N. OO.MM, Santiago, caballeros, exp. 526, año 1618 .

172. SAlAzAR y CAStro, 1704: 226.

173. A.H.N. OO.MM, Santiago, caballeros, exp. 1598, año 1630.

174. A.H.N. OO.MM, Santiago, caballeros, exp. 4574, año de 1631
} 
de Moratalla ${ }^{175}$ en agradecimiento de los buenos servicios prestados por su padre. En septiembre de I62I dejó la presidencia Fernando de Acevedo, coincidiendo con la muerte de Felipe III. Accedió entonces a la dirección de la institución Francisco de Contreras, anteriormente miembro del Consejo de Órdenes. En premio a sus años de servicio obtuvo una de las encomiendas más ricas y prestigiosas de la Orden de Santiago, la encomienda Mayor de León ${ }^{176}$, valorada a mediados del siglo XVII en aproximadamente unos 8.000 ducados anuales ${ }^{177}$.

\section{CONSIDERACIONES FINALES}

Durante el reinado de Felipe III los consejeros de Órdenes y Castilla accedieron, como hemos podido comprobar en las páginas precedentes, de forma continua y asidua a las mercedes de las órdenes militares castellanas. De entre los dieciocho miembros del consejo de órdenes que fueron nombrados durante el reinado de Felipe III, el Ioo\% obtuvo un hábito militar. El tiempo transcurrido entre el acceso del consejero a la institución y el ingreso en una de las tres órdenes militares no superó en ninguno de los casos estudiados los seis meses, por lo que en un periodo mínimo de tiempo el individuo se le concedía la merced de hábito, le eran realizadas las probanzas correspondientes, y profesionaba. En lo referente a las instituciones de acceso, la amplia mayoría de los consejeros de órdenes del reinado del tercer Felipe vistieron el hábito de Santiago, representando casi el 70\% de los hábitos concedidos a estos consejeros. Las órdenes de Calatrava y Alcántara siguen a Santiago con cifras muy alejadas, ambas dos representando tan solo un i6\% del total.

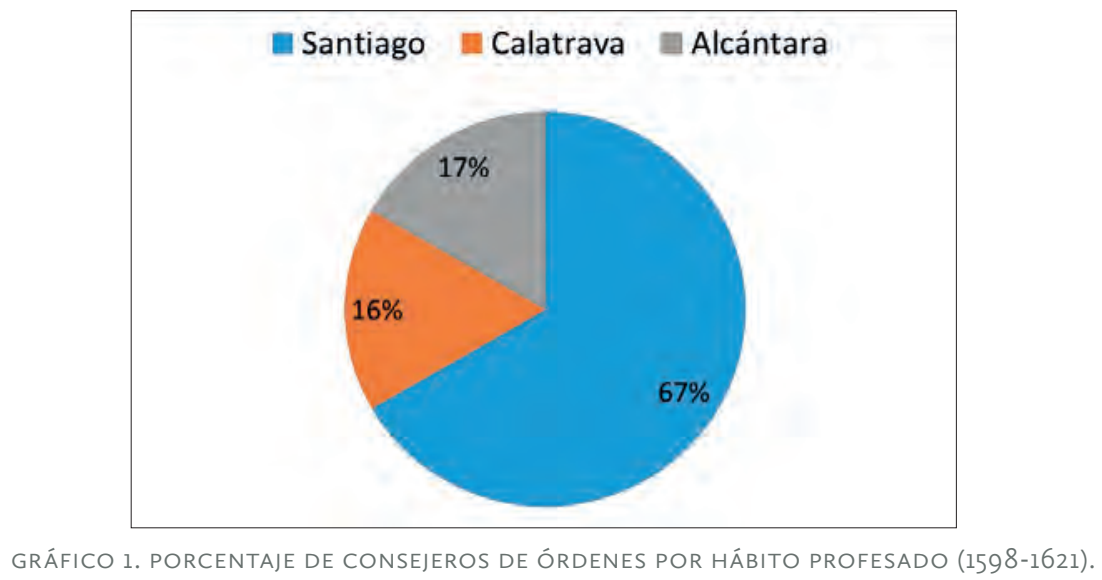

Aunque todos los consejeros de órdenes obtuvieron un hábito, no todos consiguieron de la misma forma una merced de encomienda, la más ansiada de las dignidades que poseían las órdenes militares castellanas. Solo el 56\% de los

\footnotetext{
175. SAlazAr y CASTRO, 1704: 176

176. Salazar y CaStro, 1704: 565 .

177. LóPEZ GONZÁlEZ, 1988: 395.
} 


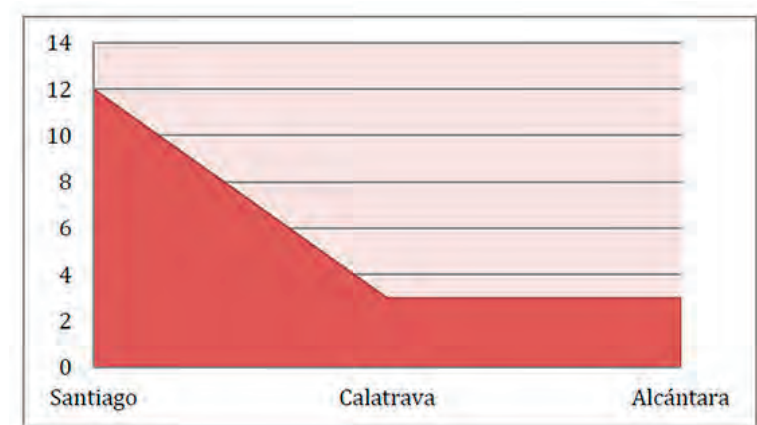

GRÁFICO 2. NÚMERO DE CONSEJEROS DE ÓRDENES POR HÁBITO PROFESADO (1598-1621).

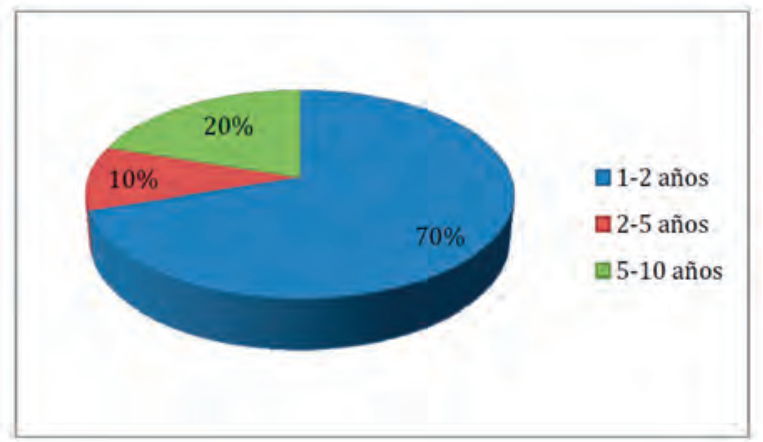

GRÁFICO 3. TIEMPO RESULTANTE ENTRE EL ACCESO AL CONSEJO DE ÓRDENES Y LA OBTENCIÓN DE UNA MERCED DE ENCOMIENDA POR LOS CONSEJEROS DE ÓRDENES (1598-1621).

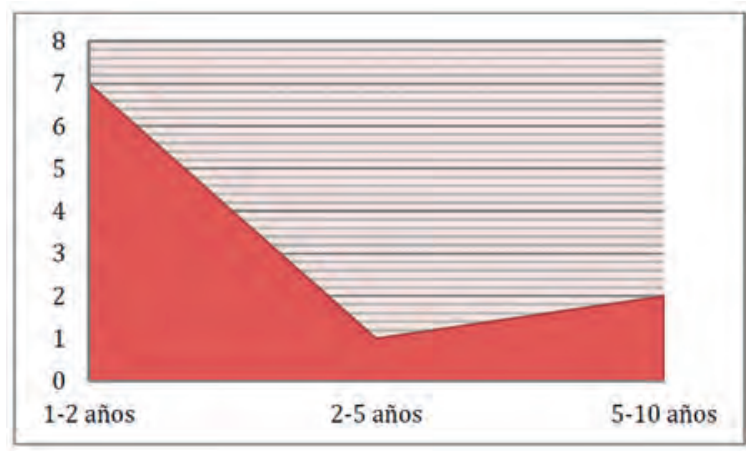

GRÁFICO 4. NÚMERO DE CONSEJEROS DE ÓRDENES BENEFICIARIOS DE UNA ENCOMIENDA Y EL TIEMPO DE CONSECUCIÓN DE LA MISMA (1598-1621).

miembros del Consejo de las Órdenes entre 1598 y i62I fueron beneficiarios de encomiendas de las órdenes como administradores o comendadores titulares de las mismas. El otro 44\% nunca llegó a acceder a estas mercedes, y tan solo lucieron los hábitos de las instituciones. De este casi 60\% de consejeros de órdenes que si tuvieron el privilegio de obtener una encomienda, el 70\% accedió a la misma en un periodo de tiempo comprendido entre uno y dos años. Un 20\%, tuvo que esperar a obtener una merced de este tipo entre cinco y diez años. Por último, el ıo\% de los consejeros agraciados tuvo que persistir alrededor de dos y cinco años administrar o ser comendador de un señorío.

En lo referente a los miembros del Consejo de Castilla, durante el reinado de Felipe III se dieron 38 nombramientos de consejeros de Castilla. De entre estos casi cuarenta 
consejeros, 25 obtuvieron un hábito de Santiago, Calatrava o Alcántara. Es decir, que el 66\% de los miembros del Consejo de Castilla entre 1598 y i62 i pertenecieron a una de las tres órdenes militares castellanas. El otro 34\% restante o no eran caballeros o profesaban hábitos de Santa María de Montesa, San Juan del Hospital o de la Orden del Toisón. De los consejeros que si accedieron a los institutos armados de Castilla, la mayoría, como en el Consejo de Órdenes, lo hicieron en la Orden de Santiago, representando esta milicia el $76 \%$ de los hábitos profesados por los consejeros de Castilla.

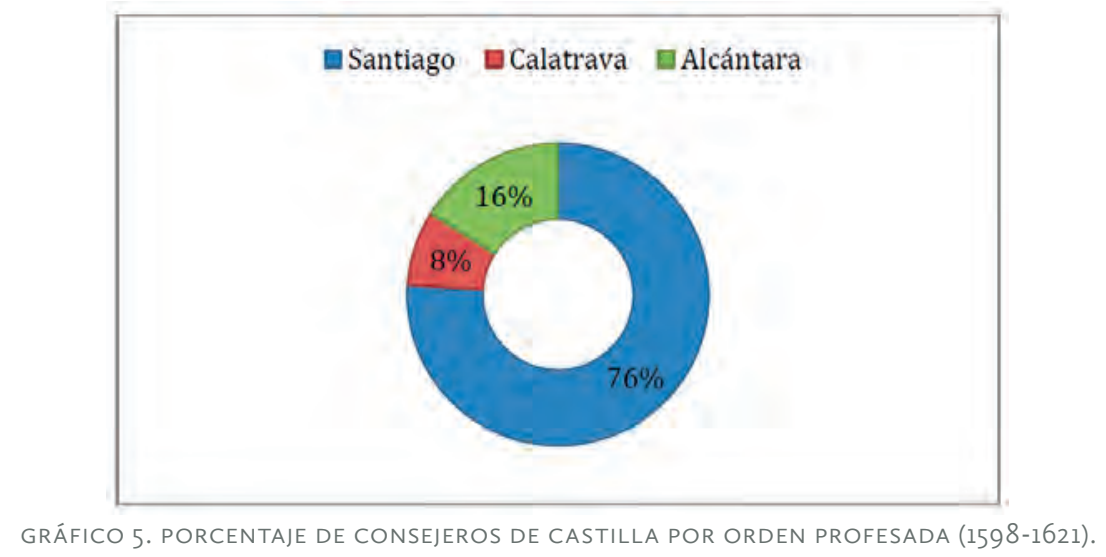

Esto supone un Io\% más que en el caso de los consejeros de órdenes. El siguiente grupo es el de los consejeros que profesaron el hábito de Alcántara, cuyo porcentaje asciende al I6\%, similar al I7\% de los miembros de órdenes. La Orden de Calatrava, una vez más, representa los datos más bajos, con tan solo un $8 \%$ de miembros del Consejo de Castilla (en órdenes posee cifras más altas, con un 9\% más).

Resulta interesante comprobar que la mayoría de los miembros de los consejos de órdenes y Castilla optaban por su pertenencia a la Orden de Santiago (67\%-76\%), y que la Orden de Calatrava (16\%-8\%) fuese la que menos adeptos atrajese dentro de estas instituciones gubernativas. La razón puede deberse a dos cuestiones. En primer lugar, que Santiago era la institución que mayor prestigio poseía en el siglo XVII, siendo el organismo preeminente de los caballeros procedentes de los ejércitos del rey católico ${ }^{178}$. Sus miembros, por tanto, encarnaban la tradición bélica y moral de los institutos armados altomedievales ${ }^{179}$. Por su parte, la Orden de Calatrava fue considerada, ya en el seiscientos, como la orden más espiritual, y la reservada a la nueva nobleza togada ${ }^{180}$. Alcántara, sin embargo, desde los inicios de la modernidad comenzó a obtener un papel cada vez más marcado como la institución de la vieja nobleza, y de los valores aristocráticos más puros y ancestrales. Además de estas consideraciones de tipo social, no podemos olvidar las puramente económicas. La Orden del apóstol era la milicia que mayor número de encomiendas poseía, casi noventa en el seiscientos, un número muy superior a las que poseían Calatrava y Alcántara, con 56

178. Véase la obra de Andrés Mendo: MENDO, 1682.

179. Postigo Castellanos, (1995): 169-204.

180. Elena Postigo, tras el estudio sistemático y exhaustivo de los expedientes de caballero de las tres órdenes militares de Castilla llegó a la confección de estos perfiles de acceso. Postigo CastelLanos, 1985. 


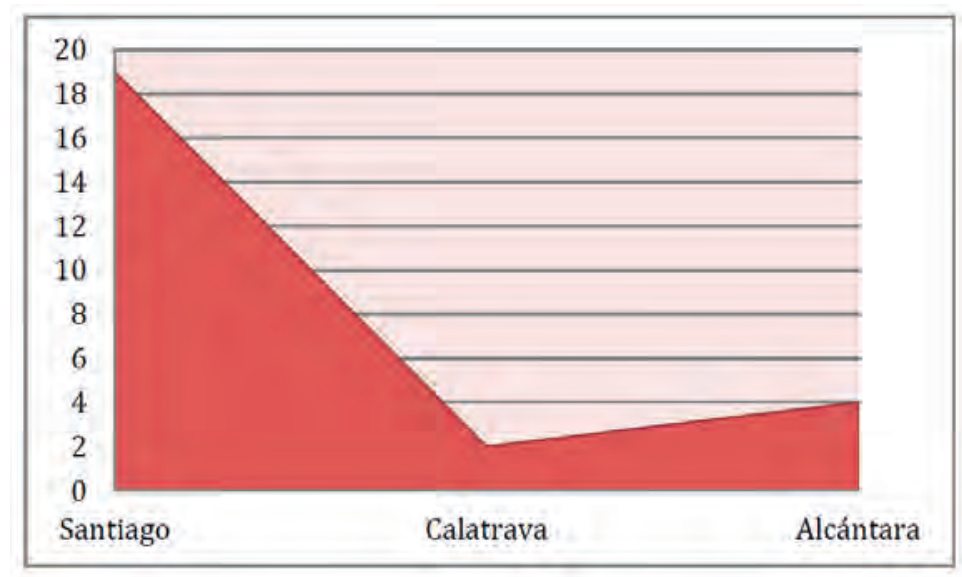

GRÁFICO 6. NÚMERO DE CONSEJEROS DE CASTILLA POR ORDEN PROFESADA (1598-1621).

y 37 respectivamente ${ }^{\mathrm{r} 8 \mathrm{r}}$. Es decir, que la probabilidad de conseguir una encomienda era mayor en Santiago, por lo que el deseo de los pretendientes se veía alimentado por dicha estadística.

Asimismo, es sugerente observar el espacio temporal comprendido entre el nombramiento y la consecución del hábito. Si el ıoo\% de los miembros del Consejo de Órdenes era beneficiario de un hábito militar en un tiempo máximo de seis meses después de obtener el cargo, hecho por el que Elena Postigo llegó a afirmar que poseer un hábito era un requisito indispensable para ser consejero de órdenes ${ }^{182}$, para los ministros del Consejo de Castilla las cifras son un tanto diferentes, aunque de fácil interpretación. El 32\% de los consejeros de Castilla agraciados con un hábito lo obtuvieron, como los consejeros de órdenes, en una horquilla comprendida entre uno y seis meses, un I6\% tuvo que esperar entre dos y cinco años, y los menos, un $12 \%$, entre cinco y diez años. La cifra que mayor interés nos suscita es ese $40 \%$ de los miembros de Castilla que ya poseían un hábito de una de las tres caballerías castellanas cuando accedieron a la institución.

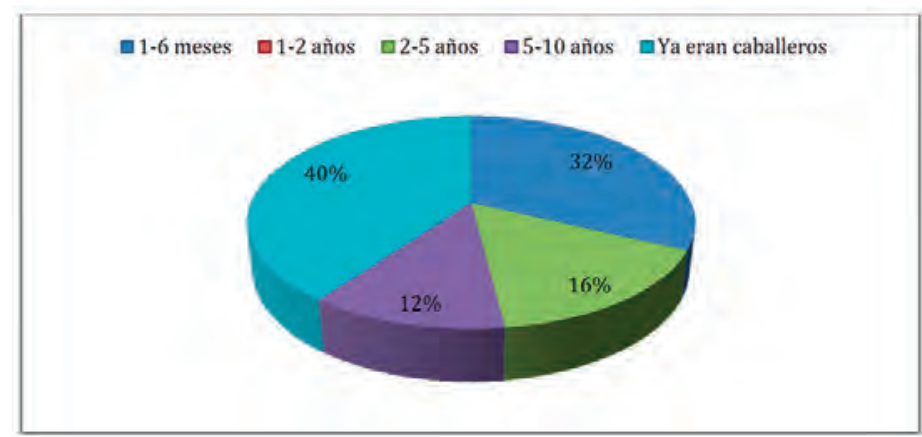

GRÁFICO 7. PORCENTAJE DE CABALLEROS MIEMBROS DEL CONSEJO DE CASTILLA CON RESPECTO AL TIEMPO DE CONSECUCIÓN DEL HÁBITO DE LA ORDEN CORRESPONDIENTE (1598-1621).

181. LóPEZ GONZÁLEZ, 1988: 390-399.

182. Postigo Castellanos, 1985. 
El cursus honorum de los consejos de la monarquía, ya demostrado por Elena Postigo $^{183}$ para el Consejo de Órdenes, y por otros autores para el resto de consejos (Feliciano Barrios ${ }^{184}$, Escudero López ${ }^{185}$, Sánchez Prieto ${ }^{186}$, etc.), también se materializa en este caso en la consecución de los hábitos de caballero. En el caso concreto del Consejo de Castilla, último escalafón de la trayectoria de un actor en el sistema polisinodial, el 40\% de los mismos ya había sido agraciado con una merced de hábito militar cuando fue nombrado consejero de Castilla. Es decir, que anteriormente habían prestado algún servicio a la Corona o al valido de turno para recibir tal premio. Para los miembros de Castilla, este $40 \%$ de consejeros que ya habían profesado en una orden provenían, casi en su totalidad, del Consejo de órdenes, que siguiendo la tesis de Postigo Castellanos, habían promocionado después de varios años en un consejo que les formaba y habilitaba para el completo gobierno de la monarquía. Si el 40\% de los consejeros de Castilla provenían de órdenes, el otro $60 \%$ provenía, en su mayoría, y gracias a los estudios de Gómez Rivero, de las reales audiencias y chancillerías. Por su parte, los consejeros de órdenes, y a la luz

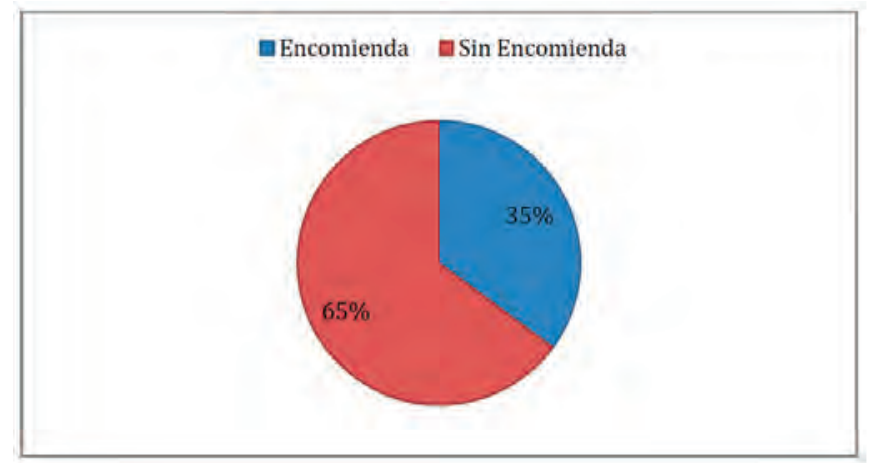

GRÁFICO 8. PORCENTAJE DE CONSEJEROS DE CASTILLA POR DISFRUTE DE ENCOMIENDA (1598-1621).

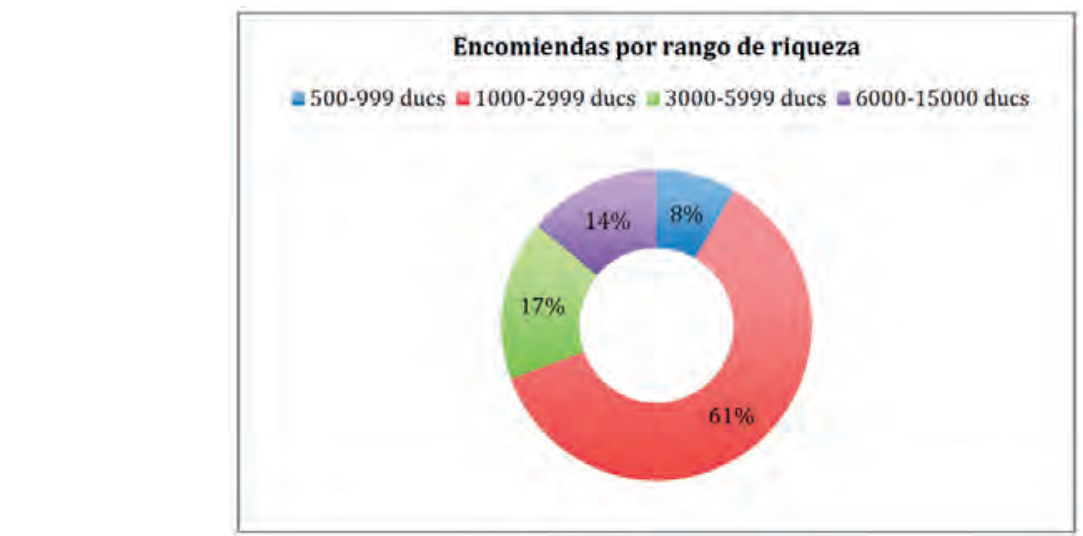

GRÁFICO 9. PORCENTAJE Y NÚMERO DE ENCOMIENDAS CONCEDIDAS A LOS MIEMBROS DE ÓRDENES Y CASTILLA POR RANGO DE RIQUEZA (1598-1621).

183. Ibídem

184. BARRIOS, 2015

185. ESCUDERO, 2008: 337-364. ESCUDERO, 2008: 319

186. SÁnChez Prieto, (2005): 380-407. 
de nuestras investigaciones, tenían dos destinos preferentes: Castilla y el Consejo de la Suprema.

Por lo que se refiere al acceso de los consejeros de Castilla a las encomiendas, máxima merced que el soberano podía ofrecer a un caballero de hábito junto con la dignidad de trece (Orden de Santiago), encontramos que fueron varios miembros de este sínodo los que se vieron agraciados de dicho privilegio durante el reinado del tercer Felipe. En total, entre I598 y i62 I fueron I3 consejeros, de un total de 37, los que obtuvieron una merced de encomienda. Es decir, el 35\% de los mismos. Estos datos contrastan con los ofrecidos por el Consejo de Órdenes, donde casi el 60\% de los consejeros disfrutaron de una encomienda en el periodo señalado. Esto nos indica que la remuneración de servicios a través de mercedes de encomienda estaba más orientada a los miembros de órdenes que a los de Castilla. En el caso de los hábitos, sin embargo, si encontramos amplias similitudes. Como indicábamos, casi el 70\% de los consejeros de Castilla fueron agraciados con hábitos militares, aparentemente la forma más usual de recompensar a estos ministros mediante estas instituciones de honor.

En lo referente a la riqueza de las encomiendas dadas en merced, observamos que los señoríos concedidos a los miembros de los consejos poseían, en su mayoría (61\%) una riqueza media, y que tan solo un $8 \%$ de las encomiendas producían bajas rentas. Un importante volumen de las mismas poseía una riqueza alta, el 31\%, de las cuales el I4\% corresponden a encomiendas que superaban los 6.00o ducados de renta anual. De esta forma, podemos afirmar que una buena parte de los señoríos más pingues de las ordenes castellanas estaban reservadas al pago de servicios de los miembros de los consejos de la monarquía, junto con otros ministros como el valido, y los servidores más cercanos del soberano, como los de palacio o la Casa del rey.

Hemos de decir, además, que la riqueza de las encomiendas expresada se remite a las averiguaciones sobre el valor de las encomiendas de las tres órdenes mandabas hacer por Felipe II a finales del años I595. Por lo tanto, tratamos valores aproximados, que fluctuaron durante la centuria siguiente. Además, los mismos son expresados en bruto, puesto que a estas rentas se les debían aplicar distintas cargas, tanto las propias inherentes de las milicias (lanzas, medias lanzas, encasamientos, medias annatas...), como los gravámenes regios (subsidio y excusado). Estos hacían menguar los ingresos de las encomiendas en, aproximadamente, un $15 \%$ de la riqueza total. Aún son necesarios, a día de hoy, estudios que ahonden en dicha cuestión, puesto que la realidad económico-fiscal de estas instituciones, y sobre todo en lo referente a las encomiendas, es en muchos casos desconocida ${ }^{187}$.

Por otro lado, hemos de comentar que el reinado de Felipe III vino acompañado de nuevas instrucciones al Consejo de Órdenes en cuanto a los procesos de probanzas y concesión de hábitos y encomiendas. Aunque en el reinado del tercer Felipe no se darán las políticas de concesión masiva de mercedes de las órdenes para pagar servicios como en el mandato de Felipe IV, es cierto que empiezan a darse las

187. Los estudios de Fernández Izquierdo, López González o Ruiz Rodríguez se orientaban en esta línea de investigación. 
bases para este sistema. Como hemos podido observar en las páginas precedentes, el gobierno de los validos instaura una utilización personalista de las mercedes de estas instituciones, acentuando las dinámicas que la propia Corona ejercía dentro del sistema de remuneración de servicios de la Monarquía tras la incorporación. Algunas instrucciones, como la siguiente, muestran la opacidad del sistema de concesión, en este caso de hábitos:

«Ordenando a los ministros superiores que no hagan intercesiones, y a los consejeros el cuidado de sus obligaciones, y particularmente al presidente, para que las diligencias se hagan con secreto, encomendándolas a personas de satisfacción»»188

Por último, las aportaciones vertidas en este estudio pueden servir para realizar un análisis comparado no solo con el resto de miembros de los consejos de la monarquía, sino también para ponerlos ante el espejo de su realidad futura. Gracias a los estudios de Janine Fayard y Rufina Rodríguez ${ }^{189}$ para los miembros del Consejo de Castilla entre i62I y I746, los de Feliciano Barrios para los consejeros en el Antiguo Régimen ${ }^{190}$, y los de Elena Postigo ${ }^{191}$ y Henar Pizarro ${ }^{192}$ para los miembros del Consejo de Órdenes en el XVII, podemos establecer cambios y permanencias no solo en el funcionamiento de estos organismos, sino también en las prácticas de concesión de mercedes y remuneración de servicios de la monarquía. Puesto que, al final, estas instituciones se desarrollaban en una estructura de poder fundamentadas en el binomio servicio-merced, lógica en la que se desenvolvían todas las relaciones entre rey y reino y patrón-cliente durante el Antiguo Régimen.

\footnotetext{
188. SÁNCHEZ PRIETO, 2005: 567.

189. Fayard y Rodríguez Sanz, 1982

190. BARRIOS, 1986: 573-582.

191. Postigo Castellanos, 1988.

192. Pizarro Llorente, 2008.
} 


\section{BIBLIOGRAFÍA}

Alvar EzQuerra, Alfredo, El duque de Lerma. Corrupción y desmoralización en la España del siglo XVII, Madrid, La esfera de los libros, 2 oıo.

Álvarez y BAENA, José Antonio, ilustres en santidad, dignidades, armas, ciencias y artes. Diccionario histórico por el orden alfabético de sus nombres que consagra al Ilmo. y Nobilísimo Ayuntamiento de la Imperial y Coronada Villa de Madrid. Madrid, Benito Cano, I789-I79I.

BARrios, Feliciano, La gobernación de la Monarquía de España. Consejos, Juntas y Secretarios de la administración de la Corte (I556-I700), Madrid, Centro de Estudios Políticos y Constitucionales, 2015.

CABrera de Córdoba, Luis, Relación de las cosas sucedidas en la Corte de España, Madrid, i863. Domínguez Ortiz, Antonio, «Valoración social de los hábitos de las Órdenes Militares en la España moderna», en Ricardo Izquierdo Benito y Francisco Ruiz Gómez (Coord.), Las Órdenes Militares en la Península Ibérica, Vol. 2, 2000: II57-II75.

ElliotT, John (Coord.), El mundo de los validos, Madrid, Taurus, I999.

Escudero López, José Antonio, Felipe II, El Rey en el despacho, Madrid, Editorial Complutense, 2002.

ESCUDERo LópEZ, José Antonio,, La nobleza y los altos cargos de la administración en la España del Antiguo Régimen, México, Biblioteca Jurídica del Instituto de Investigaciones jurídicas de la UNAM, 2009.

Escudero López, José Antonio,, Los hombres de la Monarquía Universal, Madrid, Real Academia de la Historia, 20II

FAYARD, Janine; y Rodríguez SAnz, Rufina, Los miembros del Consejo de Castilla (I62I-I746), Madrid: Siglo XXI, I982.

FERNÁNDEZ IzQUIERdo, Francisco, La Orden militar de Calatrava en el siglo XVI. Infraestructura institucional: sociología y prosopografía de sus caballeros, Madrid: Consejo Superior de Investigaciones Científicas, I992.

FERnÁNDEZ IzQUierdo, Francisco, «Nobleza y Monarquía en el siglo XVII. La concesión de encomiendas de Órdenes Militares», en Enrique Martínez Ruíz y Magdalena Pi Corrales (Coord.), España y Suecia en la época del Barroco (I600-I660), Comunidad de Madrid, Consejería de Educación y Cultura, Fundación Berndt Wistedt, I998: 52I-569.

FERnÁNDEZ IzQUiERDo, Francisco, «Qué era ser caballero de orden militar en el siglo XVI y XVII», Torre de los Lujanes, Real Sociedad Económica Matritense de Amigos del País, 49, (2003): I4I-I64.

García de Villanueva, Manuel, Origen, épocas y progresos del teatro español: discurso histórico... y un compendio de la historia general de los teatros..., Madrid, Imprenta de Gabriel de Sancha, I802.

Gomez Centurión, José, Jovellanos y las Órdenes Militares, Tomo 6i, Madrid, Boletín de la Real Academia de la Historia, I9I2.

Gómez Rivero, Ricardo, «Consejeros de Castilla de Felipe III», en Anuario de historia del derecho español, 74, (2004): 97-I38.

Gómez Rivero, Ricardo, «Consejeros de Órdenes: proceso de designación (I598-I70o)», en Hispania: revista española de historia, Vol. 63, 214, (2003): 657-674.

González Dávila, Gil, Teatro de las grandezas de la villa de Madrid corte de los reyes católicos de España..., Madrid, Imprenta de Thomas Lunti, 1623. 
González San Segundo, Miguel Ángel: «El Consejo de Aragón y la Orden de Montesa», en Anuario de historia del derecho español, 67, (1997): 901-924.

Granda Lorenzo, Sara, La presidencia del Consejo Real de Castilla (I390-I808), Madrid, Universidad Nacional de Educación a Distancia, 2006.

Lopez De Haro, Alonso, Nobiliario genealógico de los Reyes y Títulos de España, Madrid, Imprenta de Luis Sánchez, I622

Martínez Hernández, Santiago, Rodrigo Calderón. La sombra del valido: Privanza, favor y corrupción en la España de Felipe III, Madrid, Marcial Pons, 2009.

Olival, Fernanda, «La economía de la merced en la cultura política del Portugal moderno», en José Francisco Aranda Pérez y José Damián Rodrigues, (Coord.): De Re Publica Hispaniae: una vinculación de la cultura política en los reinos ibéricos en la primera modernidad, 2008: 389-408.

Pizarro Llorente, Henar: «El Consejo de las Órdenes», en José Martínez Millán (coord.): La monarquía de Felipe III. La Casa del Rey, Madrid, Fundación Mapfre, 2008.

Postigo Castellanos, Elena, Honor y privilegio en la Corona de Castilla. El Consejo de las Órdenes y los caballeros de hábito en el siglo XVII, Valladolid, Junta de Castilla y León, I988.

Postigo Castellanos, Elena, «caballeros del rey católico. Diseño de una nobleza confesional», en Hispania: revista española de historia, Vol. 55, 189, (I995): 169-204.

Postigo CAstellanos, Elena, «Y los maestres se hicieron reyes, y los reyes maestres», Militarium Ordinum Analecta, 2, (1998): 29I-320.

Postigo Castellanos, Elena, «Las tres ilustres órdenes y religiosas caballerías instituidas por los Reyes de Castilla y León: Santiago, Calatrava y Alcántara», en Studia histórica. Historia Moderna, 24, (2002): 55-72.

Rezabal y Ugarte, José de, Biblioteca de escritores que han sido individuos de los seis colegios mayores..., Madrid, Imprenta de Sancha, I805.

Rivero Gómez, Ricardo: «Consejeros de Castilla en el reinado de Felipe III», en Anuario de Historia del derecho español, 74, (2004): 97-I38.

Salazar y Castro, Luis, Los Comendadores de la Orden de Santiago en las provincias de Castilla y León, Biblioteca Nacional de España, sección manuscritos, I704.

SÁnchez Prieto, Ana Belén, «La administración real bajo los Austrias y la expedición de títulos nobiliarios», en Juan Carlos Galende Díaz (Dir.): Actas de las IV Jornadas Científicas sobre documentación de Castilla e Indias en el siglo XVI, Madrid: Editorial Complutense, 2005: 380-407.

WRIGHT, L.P: «Las Ordenes Militares en la sociedad española de los siglos XVl y XVII. La encarnación institucional de una tradición histórica», en John Elliott, Poder y Sociedad en la España de los Austrias, Barcelona, I982: 20-25. 

Monográfico - Special Issue: The Last Councillors of State before the Dynastic Change (1699) • Los últimos consejeros de Estado antes del cambio dinástico (1699

\section{Rafaella Pilo \& Christopher Storrs Introducción / Introduction}

\section{LUIS RIBOT}

El IX conde de Santisteban (1645-1716). Poder y ascenso de una Casa noble a través del servicio a la Corona / The IX Count of Santisteban (1645-1716). Power and Promotion of a Noble House through Royal Service

\section{Rocío MARTínez LóPEz}

Pedro Manuel Colón de Portugal, duque de Veragua. Un Consejero de Estado de Carlos II en un territorio en disputa / Pedro Manuel Colón de Portugal, Duke of Veragua. A State Councillor of Charles II os Spain in a Disputed Territory

\section{5}

\section{ROBERTO QUIRÓS ROSADO}

La construcción de un cursus honorum diplomático en tiempos de Carlos II: Francesco del Giudice (1684-1700) / The Construction of a Diplomatic Cursus Honorum in the Time of Charles II of Spain: Francesco del Giudice (1684-1700)

\section{DaVid Martín Marcos}

A Distant Council, Nearby Problems. The Duke of Medinaceli, Naples, and the Unity of the Spanish Monarchy, 1696-1702 / Consejo lejano, problemas cercanos. El duque de Medinaceli, Nápoles y la unidad de la Monarquía Hispánica, 1696-1702

\section{Cinzia Cremonin}

La parábola del príncipe de Vaudémont, entre austracismos e intereses personales / The Parabola of the Prince de Vaudémont between Habsbourg Alignment and Personal Interests

\section{Miscelánea $\cdot$ Miscellany}

\section{Pedro Navarro Martínez}

Travestir el crimen: el proceso judicial de la sala de Alcaldes de Casa y Corte contra Sebastián Leirado por sodomía y otros excesos (1768-1789) / Cross-Dressing the Crime: The Judicial Process of the Sala de Alcaldes de Casa y Corte against Sebastián Leirado by Sodomy and other Excesses (1768-1789)

\section{HÉctor LiNARES GonzÁlez}

Al servicio de Su Católica Majestad. La concesión de mercedes de las órdenes militares castellanas a miembros del Consejo de Órdenes y del Consejo de Castilla en el reinado de Felipe III (1598-1621) / At the Service of His Catholic Majesty. The Concession of Mercedes of the Castilian Military Orders to Members of the Council of Orders and of the Council of Castile in the Reign of Felipe III (1598-1621)
183 Hiltrud Friederich-StegmanN

Dos testimonios alemanes sobre la expulsión de los jesuitas españoles / Two German Testimonies about the Expulsion of the Spanish Jesuits

\section{Paula Ermila Rivasplata Varillas}

Algunas características del proceso de entrega de dotes a jóvenes que trabajaban en familias por la Casa de la Misericordia de Sevilla / Some Characteristics of the Process to Give Dowries to Young Women who Worked in Families by the House of Mercy of Sevilla

\section{CRISTINA Bravo Lozano}

Un patronato evanescente. La capilla española de La Haya durante la guerra de Sucesión / An evanescent patronage. The Spanish Chapel in The Hague during the War of Succession

\section{Taller de historiografía $\cdot$ Historiography Workshop}

\section{Ensayos · Essays}

24.5 Juan Eloy Gelabert, Pedro Cardim, Pablo Sánchez León \& 24.5 Pablo Fernández Albaladejo Historia en fragmentos / History in Fragments

\section{Reseñas · Book Review}

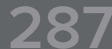
BenAVIDES MARTínez, Juan José, De milicianos del rey a soldados mexicanos. Milicias y sociedad en San Luis Potosí (1767-1824) (BEATRIz Alonso ACERo) García Espada, Antonio, El imperio mongol (Carlos Martínez SHAW)

299 Precioso IzQuierdo, Francisco, Melchor Macanaz. La derrota de un «héroe». Poder político y movilidad familiar en la España Moderna (Domingo Beltrán CoRbalÁN)

303 Rodríguez Hernández, Antonio, Sánchez Belén, Juan Antonio y Arroyo Vozmediano, Julio (eds.), Comercio, guerra y finanzas en una época en transición (siglos XVII-XVIII) (AITOR DíAZ PAREDES) reinado de Carlos // (José Mıguel López ViLLALBA) 